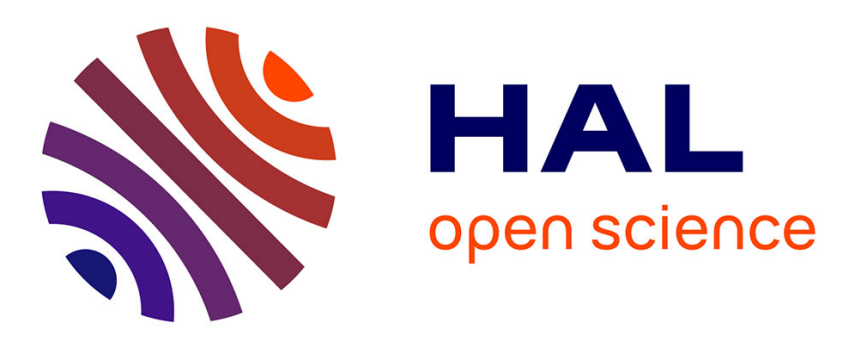

\title{
Aging behavior and modeling studies of unsaturated polyester resin and unsaturated polyester resin-based blends
}

Emmanuel Richaud, Jacques Verdu

\section{- To cite this version:}

Emmanuel Richaud, Jacques Verdu. Aging behavior and modeling studies of unsaturated polyester resin and unsaturated polyester resin-based blends. Unsaturated Polyester Resins: Fundamentals, Design, Fabrication, and Applications, Elsevier, pp.199-231, 2019, 978-012816129-6. 10.1016/B9780-12-816129-6.00009-0 . hal-02568819

\section{HAL Id: hal-02568819 \\ https://hal.science/hal-02568819}

Submitted on 10 May 2020

HAL is a multi-disciplinary open access archive for the deposit and dissemination of scientific research documents, whether they are published or not. The documents may come from teaching and research institutions in France or abroad, or from public or private research centers.
L'archive ouverte pluridisciplinaire HAL, est destinée au dépôt et à la diffusion de documents scientifiques de niveau recherche, publiés ou non, émanant des établissements d'enseignement et de recherche français ou étrangers, des laboratoires publics ou privés. 


\section{AGING BEHAVIOR AND MODELING STUDIES OF UNSATURATED POLYESTER RESIN AND UNSATURATED POLYESTER RESIN-BASED BLENDS}

Emmanuel Richaud and Jacques Verdu

PIMM, UMR 8006, ENSAM - CNRS - CNAM, HESAM Université, Paris, France

\subsection{INTRODUCTION}

Unsaturated polyester resins (UPRs) are usually obtained from a prepolymer being a condensation product of unsaturated anhydride (or diacid) and a diol. This highly viscous liquid is dissolved in a reactive low viscosity solvent, commonly styrene (or sometimes methyl methacrylate). The curing is initiated by peroxide and metallic salt catalyst of the peroxide decomposition often called "accelerator". It induces the copolymerization of double bonds hold by both the prepolymer and the solvent to give a network.

The wide use of such materials in applications ranging from tanks, tubes, and vessels to shipbuilding or outdoor swimming pools makes it necessary to well understand their long-term stability in the presence of external factors that cause degradation (temperature, oxygen, water, chemicals, radiations, etc.). The present chapter is, hence, aimed at:

- presenting the main mechanisms involved in network degradation;

- proposing kinetic schemes and providing the corresponding equations, thereby allowing for the prediction of changes in network structure (at a molecular scale) and the influence of the cited causes of degradation;

- using the available structure-property relationships or establishing empirically new ones to determine the effect of the observed changes at microscopic scale on network properties, especially thermomechanical properties.

There are basically two kinds of aging mechanisms.

1. Physical aging basically corresponds to changes in composition (water absorption, plasticizer loss) and in chain conformation, especially when interchain distances are modified, but without modification of the polymer chemical structure. The main kinds of physical aging are structural relaxation (with a decrease of free volume) and physical aging by solvent ingress or plasticizer 
loss. In this chapter, focus will be placed on humid aging, which induces plasticization and differential swelling, thereby generating strains and thus being a possible cause of matrix or fiber-matrix interfacial damage. The latter will favor water penetration into the material and thus the eventual propagation of chemical aging deep sample layers.

2. Chemical aging is due to reactions with external agents such as water, oxygen, solar UV, or ionizing radiations. Since polyesters are often used in contact with water, emphasis will be put on polyester composite interactions with water. In this chapter, particular attention will be paid to the phenomenon of osmotic cracking, in which degradation at the microscopic scale leads to the formation of macroscopic cracks.

\subsection{CHANGES IN MECHANICAL PROPERTIES OF NETWORKS}

\subsubsection{NETWORK PLASTICIZATION BY SOLVENTS}

The penetration of water or other small molecules into the polymer provokes a strong glass transition temperature $\left(T_{\mathrm{g}}\right)$ decrease illustrated, for example, in the case of UPR and its composites [1]. From a theoretical point of view, let us recall that the free volume theory allows for the change of $T_{\mathrm{g}}$ to be predicted in the case of polymer blends and polymer-solvent mixtures by the simplified relationship seen in Eq. (9.1).

$$
\frac{1}{T_{\mathrm{g}}}=\frac{1-\phi}{T_{\mathrm{gp}}}+\frac{\phi}{T_{\mathrm{gw}}}
$$

In common "dry" polyester networks, the $T_{\mathrm{g}}$ is in the order of $380 \mathrm{~K}$ and the $T_{\mathrm{gW}}$ is in the order of $120 \mathrm{~K}$. The above relationship can be rearranged as:

$$
\frac{1}{T_{\mathrm{g}}} \sim \frac{1}{T_{\mathrm{g}(\mathrm{dry})}}+0.0057 \phi
$$

Thus $T_{\mathrm{g}}$ is expected to decrease of about $8 \mathrm{~K}$ per per percent of absorbed water. In common polyesters, water absorption does not exceed 1-2\%. The effects of plasticization are thus limited, but can be critical when the material is submitted to high static loads.

Glassy modulus ( $E_{\text {glassy }}$ ) depends on the density of cohesive energy: $K \sim 11$. CED where $K$ is the bulk modulus and CED the Cohesive Energy Density [2]. In the case of plasticized networks, the interchain distance increases, so it is expected that the elastic glassy modulus decreases.

The glassy modulus $\left(E_{\mathrm{rub}}\right)$ depends on the elastically active chain concentration. It decreases with plasticizer content [3]:

$$
E_{\text {rub }}=3 \times \phi_{\mathrm{P}}^{1 / 3} \times[\mathrm{EAC}] \times R T
$$

Plastification by water, therefore, results in a decrease in mechanical properties such as glassy and rubbery elastic modulus [1,4]. Identically to $T_{\mathrm{g}}$ changes, depletions of the glassy and rubbery moduli are expected to be weak since water absorption is low. Moreover, in the absence of any other chemical damages, these changes would be characterized by:

- an equilibrium state,

- a reversible aspect. 
According to Apolinario et al. [5], the elastic modulus actually plateaus in the case of an immersion at $30^{\circ} \mathrm{C}$. The drop of elastic modulus is about $5 \%$ (for a $1 \%$ water uptake) and samples recover their initial properties after drying. However, this seems to not always be the case [1], meaning that chemical damage can overlap either in the matrix or at the matrix-fiber interface.

\subsubsection{OSMOTIC CRACKING}

Osmotic cracking has, in particular, been observed for water diffusion. Its mechanism can be summarized as follows:

- water diffuses into the polymer and fills a "void" (preexisting cavity) or forms a cluster (see Section 9.3.2);

- short soluble molecules (e.g., curing initiator byproducts, unreacted styrene, or short fragments generated from hydrolytic degradation) dissolve in this water phase and lower its chemical potential;

- this latter step provokes further diffusion of water through the polymer (which behaves as a permeable membrane) so as to equilibrate its chemical potential. The difference in chemical potential between dissolved and external water results in an osmotic pressure given by van't Hoff's law:

$$
P=R T \sum c_{\mathrm{i}}
$$

$c_{i}$ being the concentration in soluble molecules in the "cavity."

At a certain stage, the osmotic pressure exceeds the polymer stress at break, which induces an osmotic cracking. It results in a well recognizable disk crack with radial lines [6] (Fig. 9.1).

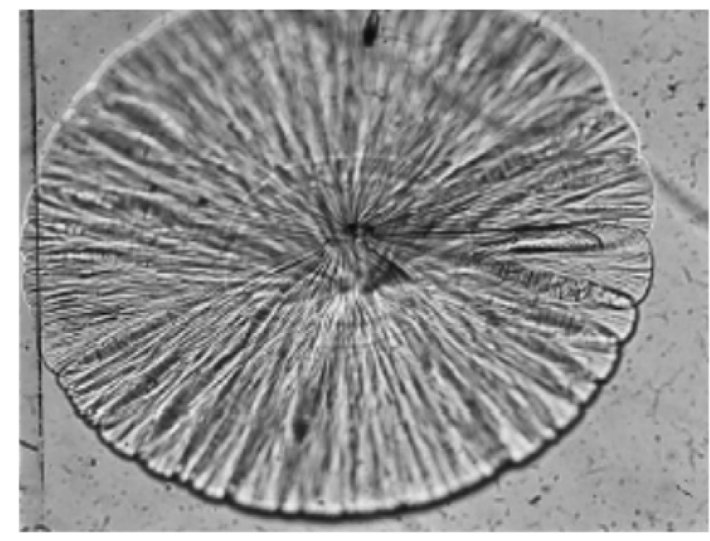

\section{FIGURE 9.1}

Microscopic observations of disk cracks for osmotic cracking. 
A rise in temperature induces an increase in water solubility in polymers and the redissolution of the water phase in polyesters and, thus, possible self-healing. Conversely, a decrease in temperature induces a supersaturation of water in polymers and the initiation of new disk cracks [7]. Last, the initiation time for disk cracks would obey the Arrhenius law [6].

\subsubsection{CHANGES INDUCED BY CHEMICAL AGING}

Jefferson et al. [1], compared the changes in $T_{\mathrm{g}}$ and elastic modulus (at glassy state) in virgin polyester materials (matrices with carbon nanofibers and/or glass fibers), those polyester materials after water immersion (weight gain about $0.1 \%-1 \%$ ), and unsaturated polyester (UP) materials immerged in water and then dried.

Their results, illustrated in Fig. 9.2, show that water penetration is not totally reversible. Comparable results were obtained for UP immersion in ethanol (Table 9.1) [8]; where mass uptake curves displayed a maximum followed by a decrease ascribed to the leaching of small molecules, and the ultimate stress decreased with ethanol aging. However, one sees that a $\sigma_{\mathrm{R}}$ decrease cannot be explained only by ethanol ingress. Actually, the decrease for $\sigma_{R}$ is observed to be lower for instances of higher ethanol uptake.

These (irreversible) changes are associated to the chemical degradation described in Section 9.3.

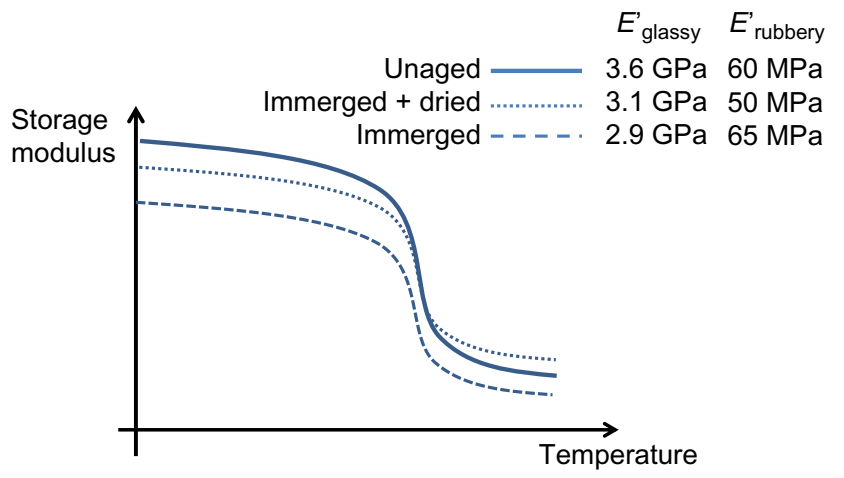

FIGURE 9.2

Effect of water immersion on modulus [8].

\begin{tabular}{|c|c|c|c|c|}
\hline \multirow[b]{2}{*}{$\boldsymbol{T}\left({ }^{\circ} \mathbf{C}\right)$} & \multicolumn{2}{|c|}{ Mass Uptake (\%) } & \multicolumn{2}{|c|}{ Ultimate Stress (MPa) } \\
\hline & 7 Days & 30 Days & 0 Days & 30 Days \\
\hline $\begin{array}{l}90 \\
115\end{array}$ & $\begin{array}{l}3.2 \\
2.5\end{array}$ & $\begin{array}{l}1 \\
0.3\end{array}$ & 393 & $\begin{array}{l}166 \\
142\end{array}$ \\
\hline
\end{tabular}


The elastic modulus at glassy state actually depends on cohesive energy more than on cross-link density. In the case of hydrolysis, moderately polar ester groups are converted into highly polar ones (carboxylic acids and alcohols). However, there are no studies evidencing an increase in glassy moduli with hydrolysis (see, e.g., Fig. 9.2 where a decrease is observed).

At temperatures above the $T_{\mathrm{g}}$, thermoset networks are in the rubbery state. Elastic behavior is given by the Flory approach, according to which the Young's modulus is proportional to the concentration of elastically active chains, $n_{0}[3]$ :

$$
E=\frac{3 \rho R T}{M_{\mathrm{C}}}=3 n_{0} R T
$$

where $\rho$ is the density, $M_{\mathrm{C}}$ the average molar mass between cross-links, $R$ the gas constant, and $T$ the absolute temperature.

Eq. (9.5) is a theoretical equation valid for ideal networks. The analysis of a wide series of UPR networks has shown that the modulus-cross-link density is rather:

$$
E=3 \rho R T \times\left(\frac{1}{M_{\mathrm{C}}}-1.5\right)
$$

illustrating the effect of dangling chains [9].

It is clear that chemical changes leading to either chain scission or cross-linking will modify the concentration of elastically active chains and later the rubbery modulus. For degraded networks having undergone chain scission $(s)$ and/or cross-linking $(x)$, it can be proposed that:

$$
n=n_{0}-\psi \times s+\phi \times x
$$

with $\psi=1$ for tetrafunctional networks and $\psi=3$ for trifunctional networks.UPR are possibly tetrafunctional networks but there are degradation studies based on these relationships.

The glass transition of a fully cured network $\left(T_{\mathrm{g} \infty}\right)$ is given by the DiMarzio's equation [10]:

$$
T_{\mathrm{g} \infty}=\frac{T_{\mathrm{gl}}}{1-K_{\mathrm{DM}} F n_{0}}
$$

where $K_{\mathrm{DM}}$ is the DiMarzio's constant; $n_{0}$ is the cross-link density (mol $\left./ \mathrm{kg}\right) ; T_{\mathrm{gl}}$ is the glass transition of a "virtual" linear polymer $\left(n_{0}=0\right) ; F$ is the flex parameter $(\mathrm{kg} / \mathrm{mol})$ related to the molar mass per rotatable bond.

The calculation of the parameters of DiMarzio's law is illustrated in the case of epoxies [11]. In the case of UPR, an attempt to describe glass transition of networks was done [12], but it seems that it is only possible to predict $T_{\mathrm{g}}$ values with $F, T_{\mathrm{gl}}$, and $n_{0}$ coming from structural considerations if $K_{\mathrm{DM}}$ is an adjustable parameter. The most obvious reason is the nonideality of polyesters and, in particular, the possible presence of cross-link nodes where:

- the cross-link bridge is made of several homopolymerized styrene (S) units, which can be considered as trifunctional:

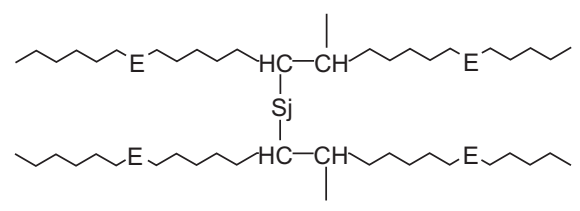


- the cross-link bridge is made of homopolymerized fumarates or maleates, which can be considered as hexafunctional:

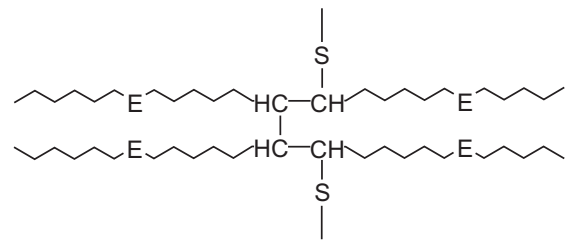

One can see here that UPRs are further from ideal networks than epoxies, for example. However, the determination of $K_{\mathrm{DM}}$ for virgin networks can allow for the estimation of the residual cross-link density after a chemical aging and later, the concentration in chain scissions and crosslinks.

$T_{\mathrm{g}}$ changes induced either by chain scission or cross-linking can be related to changes in yielding properties since it was proposed in thermosetting networks that [13]:

$$
\sigma_{\mathrm{Y}}=C\left(T_{\mathrm{g}}-T\right)
$$

and

$$
\varepsilon_{\mathrm{Y}}=\frac{\left(T_{\mathrm{g}}-T\right)}{500}
$$

Considering ultimate properties, it seems that both ultimate stress and strain decrease following the initial tensile curve of networks as a "rupture envelope" at least in the case of hydrolyzed networks (Fig. 9.3).

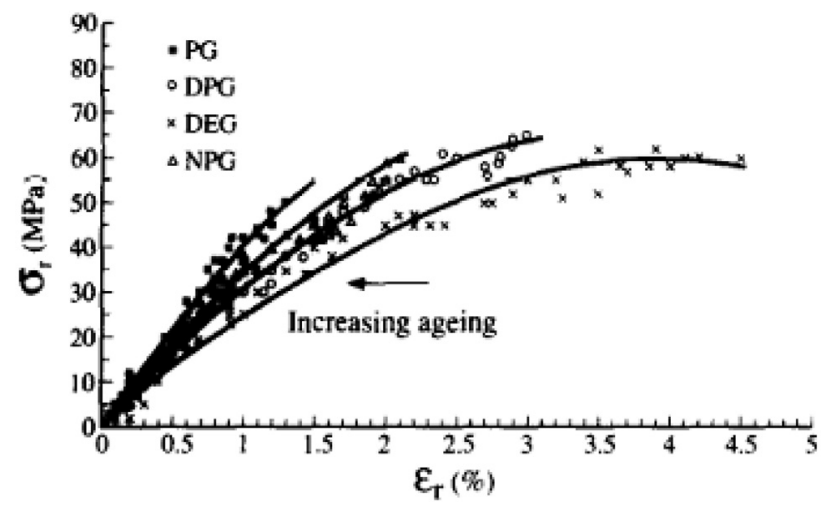

FIGURE 9.3

Decrease of ultimate stress and strain for various polyester networks having undergone various levels of hydrolysis [14]. 


\subsubsection{INTERFACIAL DAMAGES IN COMPOSITES}

In UPR-glass fiber composites, it is known that the interface is a domain where water is expected to be more soluble than in the matrix [15] as well as being subject to a faster diffusion. The consequences of aging are then worst in the case of composites in which water promotes:

- matrix-fiber decohesion [16] evidenced by a decrease in the interfacial shear strength [17]

- composite delamination [17]

- the hydrolysis of coupling agents [18]

\subsubsection{CONCLUSION}

The failure of UPR and UPR composites originate from physical aging (i.e., diffusion of small molecules in the network without changes in its architecture) and/or chemical aging (i.e., irreversible mechanisms inducing chain scissions and/or cross-linking). The main mechanisms associated with these degradation modes will be presented in Section 9.4, Mechanisms of Chemical Degradation.

Some of these changes can be described using polymer physics laws from values of water uptake or concentration in cross-link. If these latter can be described by kinetic law, it may permit the changes in engineering properties (and later the lifetime) to be predicted.

\subsection{MECHANISMS OF PHYSICAL AGING BY SOLVENT INGRESS \\ 9.3.1 COMPATIBILITY WITH ORGANIC SOLVENTS}

Sorption isotherm for organic solvents into polymers is described by the Flory-Huggins equation:

$$
\ln \left(\frac{P}{P_{0}}\right)=\ln \left(1-\phi_{\mathrm{p}}\right)+\phi_{\mathrm{p}}+\chi \phi_{\mathrm{p}}^{2}
$$

in which $P / P_{0}$ is the water activity in the external medium around the polymer; $\phi_{\mathrm{p}}$ is the polymer volume fraction in the polymer-water mixture; and $\chi$ is the polymer-solvent interaction expressing the affinity of polymers for certain chemicals ("like seeks like"). It can be calculated by:

$$
\chi=\frac{V_{\mathrm{m}}}{R T} \cdot\left(\delta_{\text {polymer }}-\delta_{\text {solvent }}\right)^{2}
$$

$\delta$ being the solubility parameter with $\delta_{\mathrm{UP}} \sim 22 \mathrm{MPa}^{1 / 2}$ [19]. Low $\chi$ values correspond to high polymer-penetrant compatibility.

It is, hence, not surprising that aromatic halogenated solvents such as chlorobenzene display a high affinity with UPR [20,21], whereas apolar solvents (cyclohexane) or highly polar solvents (water) are poorly soluble in polyesters. Extensive tables reporting the compatibility of different kinds of UPR with several sorts of fluids and chemicals can be found in Ref. [22]. 
The diffusion of solvents into UPR has been scarcely investigated in existing literature. The transport phenomena of penetrants in polymers can be described by [23]:

$$
\frac{M(t)}{M_{\infty}}=k \times t^{n}
$$

$M(t)$ and $M_{\infty}$ being the mass uptake at any time and at the theoretical equilibrium, respectively, and $n$ describing the mechanism of diffusion. Schematically:

- $n=0.5$ means that the diffusion obeys Fick's law as often observed in polymer networks when the polymer chains have a high mobility allowing an easy penetration of the solvent (with the diffusion rate, $R_{\text {diff }}$, being slower than the polymer relaxation rate, $R_{\text {relax }}$ ).

- $n=1$ means that the diffusion is either anomalous, that is, the diffusion and relaxation rates are almost of the same order or otherwise it means that the diffusion rate is much higher than the relaxation rate of a given polymer so that a sharp diffusion profile is observed.

The "diffusion" aspects will be recalled in more detail in the case of water (see Section 9.3.2). According to Deslandes, the diffusivity of chemicals in UPR is first driven by their viscosity since diffusivity increases with reciprocal viscosity [24].

The resistance to several chemicals seems to be improved by the addition of large quantities (about 40\%) of microscopic fillers such as ATH, mica, or calcium carbonate [25] or small quantities (typically 1\%-5\%) of nanoclays [26]. On the contrary, the presence of microvoids increases both the equilibrium concentration and the sorption rate [24].

\subsubsection{SORPTION AND DIFFUSION OF WATER}

Water is a highly polar solvent, therefore, its solubility in polyester is expected to be very low along with the subsequent damage. However, water is able to react with the ester groups of UPR so that the physical aging of water (reversible) is often accompanied by irreversible damages [1] occurring either in the matrix or at the fiber-matrix interface. Humid aging is, hence, by far one of the most important mechanisms for UPR degradation. Beside the chemical interaction (described in Section 9.4.1), two key parameters describe the polymer-water interaction:

- the polymer affinity with water (the hydrophilicity or solubility), and

- the rate of water penetration into the polymer matrix (the diffusivity).

\subsubsection{Solubility}

In composite matrices such as UPs, Henry's law is often used to describe the sorption of water in a matrix. It can be written as:

$$
C_{\mathrm{S}}=\sigma \times a
$$

where $C_{\mathrm{s}}$ is the equilibrium concentration of water in the polymer, $\sigma$ is the solubility coefficient, and $a$ is the activity of water (i.e., the ratio of its external pressure over the saturation pressure at the considered temperature). $\sigma$ is in the order of $0.36-0.42 \mathrm{~cm}^{3} / \mathrm{mmol}$ [27] corresponding to about $1 \%$ of water uptake after an immersion aging. The general shape of curves for water ingress is 


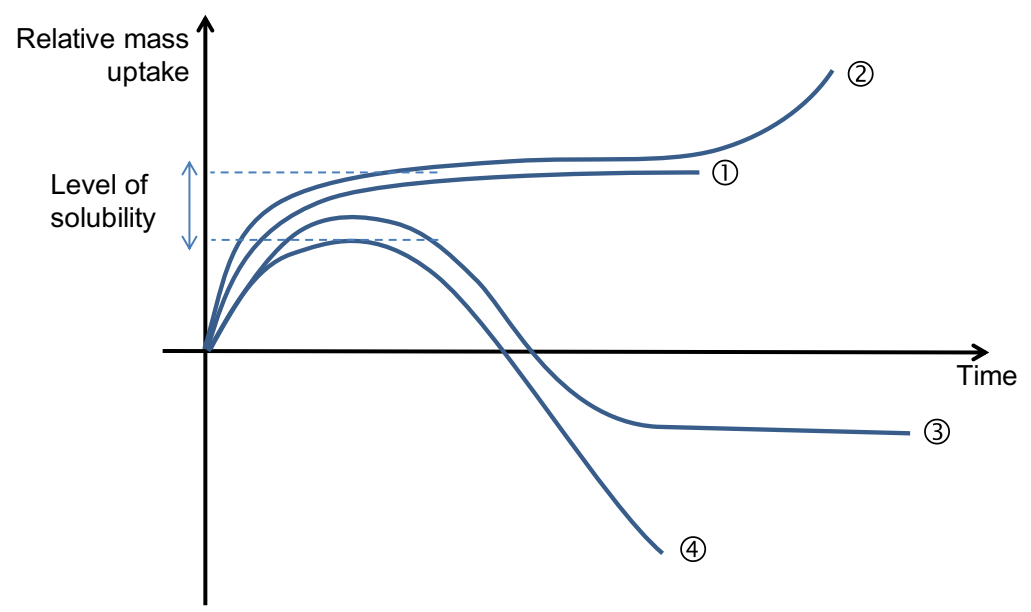

\section{FIGURE 9.4}

Theoretical shape of kinetic curves for water uptake and possible subcases. (1) Water uptake without chemical aging or leaching. (2) Water uptake followed by hydrolysis. (3) Water uptake accompanied by leaching of unreacted chemicals. (4) Water uptake followed by hydrolysis and extraction of hydrolysis byproducts.

depicted in Fig. 9.4 [28] (In some cases, the difference between type (4) and (3) curves is unclear, particularly since relatively high quantities of polymerization initiator and catalyst are used and can be extracted by surrounding water).

According to Fig. 9.4, determining the true equilibrium mass uptake is not always easy since other mechanisms can overlap, in particular the effects of hydrolysis (particularly very strong mass loss at long immersion durations) on mass uptake curves is observed only at elevated temperatures [29]. Despite this issue, the orders of magnitude of equilibrium water uptake are reported in Tables 9.2 and 9.3 together with available experimental details [27,30-32].

It is often proposed to describe water absorption in polymer by [33]:

$$
H=\frac{w_{\mathrm{m}} \times M}{1800}=\sum n_{\mathrm{i}} H_{\mathrm{i}}
$$

where $M$ is the molar mass of the repetitive unit; $n_{\mathrm{i}}$ is the number of groups able to bind with $H_{\mathrm{i}}$ molecules of water, and $w_{\mathrm{m}}$ is the equilibrium water absorption (expressed in wt.\%).

In the case of polyesters, the hydrophilicity in networks is expressed as [31]:

$$
k=k_{1} \times[\text { ester }]+k_{2} \times[\text { ether }]+k_{3} \times[\text { chain ends] }
$$

Here, the term [chain ends] accounts for acid or alcohol groups loacted at the extremity of prepolymers. More precisely, it seems that the contribution to hydrophily of those acids and alcohols is higher than ethers and esters. The effect of diacid or diol on the hydrophilicity of prepolymers has been illustrated for example in [34]. Maleates have been shown to increase the hydrophilicity either in prepolymers [34] (Fig. 9.5) or in cross-linked networks [32]. 


\begin{tabular}{|c|c|c|c|c|c|c|c|}
\hline Prepolymer & Diol & Styrene $(\%)$ & Catalyst & $\boldsymbol{T}\left({ }^{\circ} \mathbf{C}\right)$ & HR $(\%)$ & $W_{\mathrm{H} 2 \mathrm{O}}(\%)$ & \\
\hline$M(50 \%)+\mathrm{I}(50 \%)$ & PG & 38 & $\operatorname{MEKP}(1.5 \%)+\operatorname{Co}$ Oct $(0.2 \%)$ & 25 & 100 & 0.65 & [27] \\
\hline$M(50 \%)+I(50 \%)$ & PG & 38 & $\operatorname{MEKP}(1.5 \%)+\operatorname{Co}$ Oct $(0.2 \%)$ & 25 & 100 & 0.56 & [27] \\
\hline$M(50 \%)+I(50 \%)$ & PG & 38 & $\operatorname{MEKP}(1.5 \%)+\operatorname{Co}$ Oct $(0.2 \%)$ & 25 & 100 & 0.85 & [30] \\
\hline$M(46 \%)+I(54 \%)$ & PG & 44 & $\operatorname{MEKP}(1.5 \%)+\operatorname{Co}$ Oct $(0.5 \%)$ & 30 & 100 & 0.72 & [31] \\
\hline$M(46 \%)+I(54 \%)$ & PG & 44 & $\operatorname{MEKP}(1.5 \%)+\operatorname{Co}$ Oct $(0.5 \%)$ & 40 & 100 & 0.89 & [31] \\
\hline$M(46 \%)+I(54 \%)$ & PG & 44 & $\operatorname{MEKP}(1.5 \%)+\operatorname{Co}$ Oct $(0.5 \%)$ & 50 & 100 & 0.91 & [31] \\
\hline$M(46 \%)+I(54 \%)$ & PG & 42 & $\operatorname{MEKP}(1.5 \%)+\operatorname{Co}$ Oct $(0.5 \%)$ & 30 & 100 & 0.84 & [31] \\
\hline$M(46 \%)+I(54 \%)$ & PG & 42 & $\operatorname{MEKP}(1.5 \%)+\operatorname{Co}$ Oct $(0.5 \%)$ & 40 & 100 & 1.02 & [31] \\
\hline$M(46 \%)+I(54 \%)$ & PG & 42 & $\operatorname{MEKP}(1.5 \%)+\operatorname{Co}$ Oct $(0.5 \%)$ & 50 & 100 & 1 & [31] \\
\hline$M(46 \%)+I(54 \%)$ & PG & 40 & $\operatorname{MEKP}(1.5 \%)+\operatorname{Co}$ Oct $(0.5 \%)$ & 30 & 100 & 1.12 & [31] \\
\hline$M(46 \%)+I(54 \%)$ & PG & 40 & $\operatorname{MEKP}(1.5 \%)+\operatorname{Co}$ Oct $(0.5 \%)$ & 40 & 100 & 1.36 & [31] \\
\hline$M(46 \%)+I(54 \%)$ & PG & 40 & $\operatorname{MEKP}(1.5 \%)+\operatorname{Co}$ Oct $(0.5 \%)$ & 50 & 100 & 1.44 & [31] \\
\hline$M(70 \%)+I(30 \%)$ & PG & 45 & $\operatorname{MEKP}(1.5 \%)+\operatorname{Co}$ Oct $(0.5 \%)$ & 30 & 100 & 1.12 & [31] \\
\hline$M(70 \%)+I(30 \%)$ & PG & 45 & $\operatorname{MEKP}(1.5 \%)+\operatorname{Co}$ Oct $(0.5 \%)$ & 40 & 100 & 1.36 & [31] \\
\hline$M(70 \%)+I(30 \%)$ & PG & 45 & $\operatorname{MEKP}(1.5 \%)+\operatorname{Co}$ Oct $(0.5 \%)$ & 50 & 100 & 1.44 & [31] \\
\hline$M(46 \%)+I(54 \%)$ & NPG & 45 & $\operatorname{MEKP}(1.5 \%)+\operatorname{Co}$ Oct $(0.5 \%)$ & 30 & 100 & 0.47 & [31] \\
\hline$M(46 \%)+I(54 \%)$ & NPG & 45 & $\operatorname{MEKP}(1.5 \%)+\operatorname{Co}$ Oct $(0.5 \%)$ & 40 & 100 & 0.56 & [31] \\
\hline$M(46 \%)+I(54 \%)$ & NPG & 45 & $\operatorname{MEKP}(1.5 \%)+\operatorname{Co}$ Oct $(0.5 \%)$ & 50 & 100 & 0.75 & [31] \\
\hline$M(46 \%)+I(54 \%)$ & DEG & 38 & $\operatorname{MEKP}(1.5 \%)+\operatorname{Co}$ Oct $(0.5 \%)$ & 30 & 100 & 1.06 & [31] \\
\hline$M(46 \%)+I(54 \%)$ & DEG & 38 & $\operatorname{MEKP}(1.5 \%)+\operatorname{Co}$ Oct $(0.5 \%)$ & 40 & 100 & 1.29 & [31] \\
\hline$M(46 \%)+I(54 \%)$ & DEG & 38 & $\operatorname{MEKP}(1.5 \%)+\operatorname{Co}$ Oct $(0.5 \%)$ & 50 & 100 & 1.58 & [31] \\
\hline$M(46 \%)+I(54 \%)$ & DPG & 42 & $\operatorname{MEKP}(1.5 \%)+\operatorname{Co}$ Oct $(0.5 \%)$ & 30 & 100 & 0.74 & [31] \\
\hline$M(46 \%)+I(54 \%)$ & DPG & 42 & $\operatorname{MEKP}(1.5 \%)+\operatorname{Co}$ Oct $(0.5 \%)$ & 40 & 100 & 0.92 & [31] \\
\hline$M(46 \%)+I(54 \%)$ & DPG & 42 & $\operatorname{MEKP}(1.5 \%)+\operatorname{Co}$ Oct $(0.5 \%)$ & 50 & 100 & 1.14 & [31] \\
\hline$M(46 \%)+I(54 \%)$ & PG & 43 & $\operatorname{MEKP}(1.5 \%)+\operatorname{Co}$ Oct $(0.5 \%)$ & 30 & 100 & 0.97 & [31] \\
\hline$M(46 \%)+$ I $(54 \%)$ & PG & 43 & $\operatorname{MEKP}(1.5 \%)+\operatorname{Co}$ Oct $(0.5 \%)$ & 40 & 100 & 0.92 & [31] \\
\hline$M(46 \%)+I(54 \%)$ & PG & 43 & $\operatorname{MEKP}(1.5 \%)+\operatorname{Co}$ Oct $(0.5 \%)$ & 50 & 100 & 1.16 & [31] \\
\hline$M+I$ & PG & 45 & $\operatorname{MEKP}(1.5 \%)+\operatorname{Co}$ Oct $(0.5 \%)$ & 30 & 95 & 0.85 & [32] \\
\hline$M+I$ & PG & 45 & $\operatorname{MEKP}(1.5 \%)+\operatorname{Co}$ Oct $(0.5 \%)$ & 50 & 95 & 0.83 & [32] \\
\hline$M+I$ & PG & 45 & $\operatorname{MEKP}(1.5 \%)+\operatorname{Co}$ Oct $(0.5 \%)$ & 70 & 95 & 1.08 & [32] \\
\hline
\end{tabular}




\begin{tabular}{|c|c|c|c|c|c|c|c|}
\hline$M+I$ & PG & 45 & $\operatorname{MEKP}(1.5 \%)+\operatorname{Co}$ Oct $(0.5 \%)$ & 90 & 95 & 1.25 & {$[32]$} \\
\hline$M+I$ & $\mathrm{PG}+\mathrm{NPG}$ & 38 & $\operatorname{MEKP}(1.5 \%)+\operatorname{Co}$ Oct $(0.5 \%)$ & 30 & 95 & 0.94 & [32] \\
\hline$M+I$ & $\mathrm{PG}+\mathrm{NPG}$ & 38 & $\operatorname{MEKP}(1.5 \%)+$ Co Oct $(0.5 \%)$ & 50 & 95 & 1.08 & [32] \\
\hline$M+I$ & $\mathrm{PG}+\mathrm{NPG}$ & 38 & $\operatorname{MEKP}(1.5 \%)+\operatorname{Co}$ Oct $(0.5 \%)$ & 70 & 95 & 1.1 & [32] \\
\hline$M+I$ & $\mathrm{PG}+\mathrm{NPAG}$ & 38 & $\operatorname{MEKP}(1.5 \%)+\operatorname{Co}$ Oct $(0.5 \%)$ & 90 & 95 & 1.32 & [32] \\
\hline M & PG & 40 & $\operatorname{MEKP}(1.5 \%)+$ Co Oct $(0.5 \%)$ & 30 & 95 & 3 & {$[32]$} \\
\hline M & PG & 40 & $\operatorname{MEKP}(1.5 \%)+\operatorname{Co}$ Oct $(0.5 \%)$ & 50 & 95 & 3.1 & [32] \\
\hline M & PG & 40 & $\operatorname{MEKP}(1.5 \%)+$ Co Oct $(0.5 \%)$ & 70 & 95 & 2.8 & [32] \\
\hline M & NPG & 40 & $\operatorname{MEKP}(1.5 \%)+$ Co Oct $(0.5 \%)$ & 30 & 95 & 1.7 & [32] \\
\hline M & NPG & 40 & $\operatorname{MEKP}(1.5 \%)+$ Co Oct $(0.5 \%)$ & 50 & 95 & 1.7 & [32] \\
\hline M & NPG & 40 & $\operatorname{MEKP}(1.5 \%)+\operatorname{Co} \operatorname{Oct}(0.5 \%)$ & 70 & 95 & 1.8 & [32] \\
\hline
\end{tabular}




\begin{tabular}{|c|c|c|c|c|c|}
\hline Prepolymer & Catalyst & $\boldsymbol{T}\left({ }^{\circ} \mathbf{C}\right)$ & HR $(\%)$ & Isotherm & $W_{\mathrm{H} 2 \mathrm{O}}(\% \mathrm{w} / \mathrm{w})$ \\
\hline $\mathrm{O}(60 \%)+\mathrm{M}(40 \%)$ & $\operatorname{MEKP}(1 \%)+\mathrm{CN}(0.3 \%)+\mathrm{DMA}(0.05 \%) \mathrm{AC}$ & 30 & 75 & (1) & 0.8 \\
\hline $\mathrm{O}(60 \%)+\mathrm{M}(40 \%)$ & $\operatorname{MEKP}(1 \%)+\mathrm{CN}(0.3 \%)+\mathrm{DMA}(0.05 \%) \mathrm{PC}$ & 30 & 75 & (1) & 0.8 \\
\hline $\mathrm{O}(60 \%)+\mathrm{M}(40 \%)$ & $\mathrm{BPO}(1 \%)+\mathrm{DMA}(0.3 \%) \mathrm{AC}$ & 30 & 75 & (3) & 0.8 \\
\hline $\mathrm{O}(60 \%)+\mathrm{M}(40 \%)$ & $\mathrm{BPO}(1 \%)+\mathrm{DMA}(0.3 \%) \mathrm{PC}$ & 30 & 75 & (4) & 0.7 \\
\hline I & $\mathrm{BPO}(2 \%)+\mathrm{DMA}(0.3 \%) \mathrm{AC}$ & 30 & 75 & (1) & 0.6 \\
\hline I & $\mathrm{BPO}(2 \%)+\mathrm{DMA}(0.3 \%) \mathrm{PC}$ & 30 & 75 & (1) & 0.5 \\
\hline I & $\operatorname{MEKP}(0.5 \%)+\mathrm{CN}(0.3 \%)+\mathrm{DMA}(0.05 \%) \mathrm{AC}$ & 30 & 75 & (1) & 0.4 \\
\hline I & $\operatorname{MEKP}(0.5 \%)+\mathrm{CN}(0.3 \%)+\mathrm{DMA}(0.05 \%) \mathrm{PC}$ & 30 & 75 & (1) & 0.5 \\
\hline I & $\operatorname{MEKP}(4 \%)+\mathrm{CN}(0.3 \%)+\mathrm{DMA}(0.1 \%) \mathrm{AC}$ & 30 & 75 & (1) & 0.55 \\
\hline $\mathrm{O}(60 \%)+\mathrm{M}(40 \%)$ & $\operatorname{MEKP}(1 \%)+\mathrm{CN}(0.3 \%)+\mathrm{DMA}(0.05 \%) \mathrm{AC}$ & 65 & 75 & (2) & 1 \\
\hline $\mathrm{O}(60 \%)+\mathrm{M}(40 \%)$ & $\operatorname{MEKP}(1 \%)+\mathrm{CN}(0.3 \%)+\mathrm{DMA}(0.05 \%) \mathrm{PC}$ & 65 & 75 & (2) & 1.3 \\
\hline $\mathrm{O}$ & $\mathrm{BPO}(1 \%)+\mathrm{DMA}(0.3 \%) \mathrm{AC}$ & 65 & 75 & (4) & 0.6 \\
\hline $\mathrm{O}$ & $\mathrm{BPO}(1 \%)+\mathrm{DMA}(0.3 \%) \mathrm{PC}$ & 65 & 75 & (4) & 1 \\
\hline I & $\operatorname{MEKP}(4 \%)+\mathrm{CN}(0.3 \%)+\mathrm{DMA}(0.1 \%) \mathrm{PC}$ & 65 & 75 & (1) & 1 \\
\hline I & $\operatorname{MEKP}(0.5)+\mathrm{CN}(0.3 \%)+\mathrm{DMA}(0.05 \%) \mathrm{PC}$ & 65 & 75 & (1) & 1 \\
\hline I & $\operatorname{MEKP}(0.5)+\mathrm{CN}(0.3 \%)+\mathrm{DMA}(0.05 \%) \mathrm{AC}$ & 65 & 75 & (4) & 0.75 \\
\hline I & $\mathrm{BPO}(2 \%)+\mathrm{DMA}(0.3 \%) \mathrm{AC}$ & 65 & 75 & (4) & 0.7 \\
\hline I & $\mathrm{BPO}(2 \%)+\mathrm{DMA}(0.3 \%) \mathrm{PC}$ & 65 & 75 & (4) & 0.7 \\
\hline
\end{tabular}




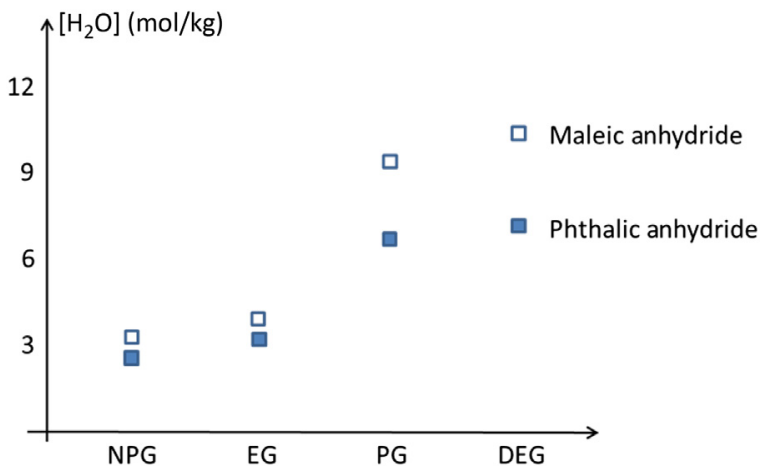

FIGURE 9.5

Hydrophilicity of prepolymer as a function of diacid or diol.

According to Table 9.2, increasing the styrene (S) content induces a decrease in maximal water uptake consistently with the fact that $S$ units are almost apolar and unable to interact with water molecules. It was even proposed that:

$$
w_{\max }=\frac{w_{\max \text { prepol }}}{(1-s)}
$$

Where $s$ is the styrene weight fraction.

It is, however, difficult to correlate the polyester hydrophilicity with prepolymer one: it was for example observed that prepolymers are almost 3-times more hydrophilic than corresponding polymerized network [34]. Two reasons are proposed: first, copolymerization with styrene induces a certain hindrance of the ester groups decreasing their affinity to water, and secondly, there is no obvious link between water affinity of prepolymer being at rubbery state and networks being usually in glassy state.

According to Table 9.3, there is a small but positive effect of postcuring on the affinity of polyesters to water (i.e., water uptake increases with post curing). Two reasons might be envisaged:

- post curing generates groups with a higher affinity to water (e.g., it can be imagined that the ester groups held by maleate are less hydrophilic than the succinate groups obtained after polymerization of the double bonds).

- the disappearance of unreacted groups (e.g., styrene) is higher in incompletely cured UPRs, which lowers the maximal level of mass uptake and permits a shift from strong type (4) behavior (Fig. 9.4) to more moderate behavior, that is, type (4) curves with a lower rate of mass depletion or even type (3) curves.

From Eq. (9.13), the effect of temperature is expected to obey Arrhenius law [35]:

$$
C_{\mathrm{S}}=C_{0} \times \exp \left(\frac{-E}{R T}\right)
$$

where $E=E_{\mathrm{S}}+E_{\mathrm{P}}, E_{\mathrm{S}}$ and $E_{\mathrm{P}}$ being the activation energies, respectively, for solubility coefficient and for water vapor pressure. The fact that the equilibrium concentration increases with temperature for any given kind of UP network [31,32] means that $E_{\mathrm{S}}+E_{\mathrm{P}}>0$, that is, $E_{\mathrm{S}}>-43 \mathrm{~kJ} / \mathrm{mol}$ [35]. 


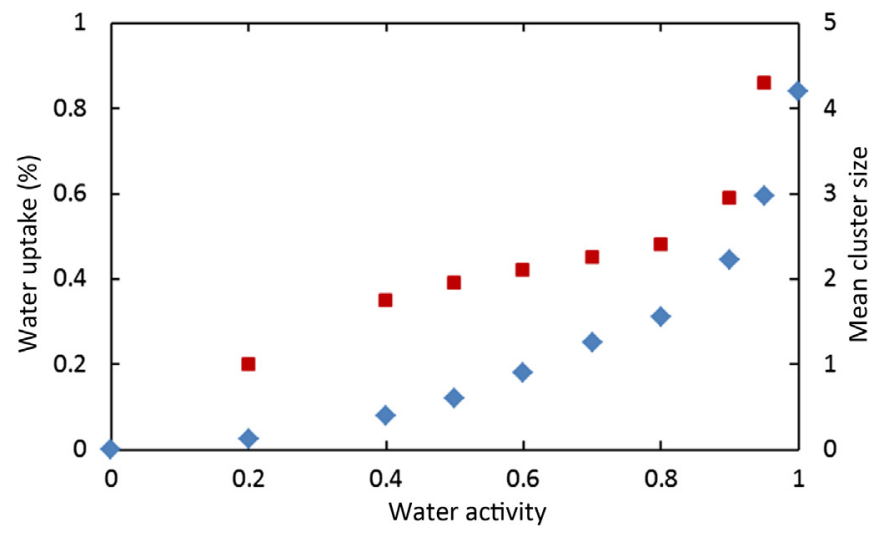

FIGURE 9.6

Sorption isotherm of water in Unsaturated Polyester Resin (UPR) together with the estimation of mean cluster size [30].

Henry's law means that the sorption isotherm displays a linear shape. However, experimental data sometimes display a positive curvature (Fig. 9.6). If the latter cannot be fitted by Eq. (9.10) with a fixed $\chi$ value (or rather that $\chi$ decreases with water affinity), it means that water first dissolves randomly in the polymer matrix (at low water activity) and then forms clusters, that is, aggregates of dimers or trimers or more water molecules (at higher water activity).

The presence of clusters can be evidenced either:

- experimentally using dielectric spectroscopy [36] or FTIR [37], or

- theoretically from Zimm-Lundberg analysis allowing for the assessment of the MCS (mean cluster size) $[38,39]$ from the clustering function:

$$
f_{\mathrm{ZL}}=\frac{G_{11}}{\nu_{1}}=-\left(1-\phi_{1}\right) \times\left[\frac{\partial a_{1} / \phi_{1}}{\partial a_{1}}\right]_{T, P}-1
$$

where $G_{11}$ is a cluster integral for water and $\nu_{1}$ and $\varphi_{1}$ are the partial molecular volume and volume fraction of water, respectively. When $f_{\mathrm{ZL}}$ is below -1 value, no clustering occurs. MCS is thus given by:

$$
\mathrm{MCS}=1+\phi_{1} \times\left(\frac{G_{11}}{\nu_{1}}\right)
$$

MCS can also be estimated from $\chi$ values used for simulating the sorption isotherm:

$$
\operatorname{MCS}=\frac{1}{1-2 \chi \phi_{1}+\left(1-\phi_{1}\right) \cdot\left(\frac{\partial \chi}{\partial \ln \phi_{1}}\right)_{T, P}}
$$

Fillers usually reduce the permeation of water (and many other chemicals) [40]. It seems, however, that there is an optimum effect. In the case of highly filled UP composites, the water uptake is even shown to clearly increase with filler content [41]. This can be explained by the 
competition of two phenomena. First, fillers increase tortuosity [42] and maybe decrease the hydrophilicity of matrices, second, however, their presence favors the existence of an interface where water is preferentially absorbed and diffuses faster [15]. Natural fibers promote strong water absorption [43].

The case of interpenetrating polymer networks (IPNs) was illustrated in studies dealing with vinyl ester networks (BisGMA cured with styrene) mixed with epoxy systems. Interestingly, it seems that the water uptake for 50:50 networks made of epoxy/diamine and polyester is closer to values observed for epoxy/diamine. It is hence suggested that blending only affects the preexponential factor (see Eq. 9.18) rather than the activation energy [44].

\subsubsection{Diffusivity}

Several models describe the rate of water diffusion in polymers:

1. Case I diffusion is observed when the characteristic time for diffusion is shorter than the typical time of polymer motions. In this case, the rate of water uptake, $M(t) / M_{\infty}$, increases linearly with time.

2. Fick's law is observed when the characteristic time for diffusion is higher than the typical time of polymer motions. In this case, the rate of water uptake, $M(t) / M_{\infty}$, increases linearly with the square root of the time. Another key characteristic of Fickian diffusion is the existence of a plateau at a long exposure time (contrarily to Langmuir diffusion).

Relative mass uptake can be simulated from the analytical resolution of Fick's law [45]:

$$
\frac{M(t)}{M_{\infty}}=1-\left(\frac{8}{\pi^{2}}\right) \times \sum_{n=0}^{\infty}\left(\frac{1}{(2 n+1)^{2}}\right) \times \exp \left(-\frac{D \times(2 n+1)^{2} \times \pi^{2} \times t}{4 e^{2}}\right)
$$

If the relative mass uptake linearly increases with the square root of time, the diffusion obeys Fick's law and $D$ can be calculated from the slope. This equation actually admits an approximate solution for low levels of water sorption $\left(M / M_{\infty}<0.6\right)$ :

$$
\frac{M(t)}{M_{\infty}}=\frac{4}{e} \times \sqrt{\frac{D \times t}{\pi}}
$$

3. The "Langmuir" law is observed when the water diffusing in a given polymer is either "free" or "bound," that is, if it displays some "strong" interactions with some sites of the polymer structure (e.g., water-unreacted oxiranes in the case of epoxy/diamine matrices) [46]. One of its main experimental features is the existence of a double sorption plateau. There is, however, no evidence of "Langmuir" diffusion in polyesters.

Experimentally, the linearity of mass uptake versus square root of the time is sometimes an approximation. However, most authors have assumed the diffusion obeys Fick's law so as to assess the diffusivity values given in Table 9.4.

Despite the experimental scattering [31], it seems that $D$ obeys Arrhenius law:

$$
D=D_{0} \times \exp \left(\frac{-E_{D}}{R T}\right)
$$

For the materials given in Table $9.3, E_{\mathrm{D}}$ takes a value close to $25-30 \mathrm{~kJ} / \mathrm{mol}$. 


\begin{tabular}{|c|c|c|c|c|c|}
\hline Prepolymer & Diol & Styrene $(\%)$ & Catalyst & $\boldsymbol{T}\left({ }^{\circ} \mathbf{C}\right)$ & $D\left(\mathrm{~mm}^{2} / \mathbf{s}^{1}\right)$ \\
\hline$M(46 \%)+\mathrm{I}(54 \%)$ & PG & 44 & $\operatorname{MEKP}(1.5 \%)+$ Co Oct $(0.5 \%)$ & 30 & $6.9 \times 10^{-9}$ \\
\hline$M(46 \%)+\mathrm{I}(54 \%)$ & PG & 44 & $\operatorname{MEKP}(1.5 \%)+$ Co Oct $(0.5 \%)$ & 40 & $12 \times 10^{-9}$ \\
\hline$M(46 \%)+$ I $(54 \%)$ & PG & 44 & $\operatorname{MEKP}(1.5 \%)+$ Co Oct $(0.5 \%)$ & 50 & $(14-19) \times 10^{-9}$ \\
\hline$M(46 \%)+\mathrm{I}(54 \%)$ & PG & 42 & $\operatorname{MEKP}(1.5 \%)+\operatorname{Co}$ Oct $(0.5 \%)$ & 30 & $5.6 \times 10^{-9}$ \\
\hline$M(46 \%)+I(54 \%)$ & PG & 42 & $\operatorname{MEKP}(1.5 \%)+\operatorname{Co}$ Oct $(0.5 \%)$ & 40 & $8.6 \times 10^{-9}$ \\
\hline$M(46 \%)+\mathrm{I}(54 \%)$ & PG & 42 & $\operatorname{MEKP}(1.5 \%)+\operatorname{Co}$ Oct $(0.5 \%)$ & 50 & $10 \times 10^{-9}$ \\
\hline$M(46 \%)+\mathrm{I}(54 \%)$ & PG & 40 & $\operatorname{MEKP}(1.5 \%)+$ Co Oct $(0.5 \%)$ & 30 & $2.1 \times 10^{-9}$ \\
\hline$M(46 \%)+I(54 \%)$ & PG & 40 & $\operatorname{MEKP}(1.5 \%)+$ Co Oct $(0.5 \%)$ & 40 & $2.7 \times 10^{-9}$ \\
\hline$M(46 \%)+\mathrm{I}(54 \%)$ & PG & 40 & $\operatorname{MEKP}(1.5 \%)+\operatorname{Co}$ Oct $(0.5 \%)$ & 50 & $3.8 \times 10^{-9}$ \\
\hline$M(70 \%)+I(30 \%)$ & PG & 45 & $\operatorname{MEKP}(1.5 \%)+\operatorname{Co}$ Oct $(0.5 \%)$ & 30 & $10 \times 10^{-9}$ \\
\hline$M(70 \%)+\mathrm{I}(30 \%)$ & PG & 45 & $\operatorname{MEKP}(1.5 \%)+\operatorname{Co}$ Oct $(0.5 \%)$ & 40 & $13 \times 10^{-9}$ \\
\hline$M(70 \%)+I(30 \%)$ & PG & 45 & $\operatorname{MEKP}(1.5 \%)+$ Co Oct $(0.5 \%)$ & 50 & $22 \times 10^{-9}$ \\
\hline$M(46 \%)+\mathrm{I}(54 \%)$ & NPG & 45 & $\operatorname{MEKP}(1.5 \%)+\operatorname{Co}$ Oct $(0.5 \%)$ & 30 & $10 \times 10^{-9}$ \\
\hline$M(46 \%)+I(54 \%)$ & NPG & 45 & $\operatorname{MEKP}(1.5 \%)+$ Co Oct $(0.5 \%)$ & 40 & $13 \times 10^{-9}$ \\
\hline$M(46 \%)+I(54 \%)$ & NPG & 45 & $\operatorname{MEKP}(1.5 \%)+$ Co Oct $(0.5 \%)$ & 50 & $18 \times 10^{-9}$ \\
\hline$M(46 \%)+I(54 \%)$ & DEG & 38 & $\operatorname{MEKP}(1.5 \%)+$ Co Oct $(0.5 \%)$ & 30 & $6.8 \times 10^{-9}$ \\
\hline$M(46 \%)+\mathrm{I}(54 \%)$ & DEG & 38 & $\operatorname{MEKP}(1.5 \%)+\operatorname{Co}$ Oct $(0.5 \%)$ & 40 & $11 \times 10^{-11}$ \\
\hline$M(46 \%)+I(54 \%)$ & DEG & 38 & $\operatorname{MEKP}(1.5 \%)+$ Co Oct $(0.5 \%)$ & 50 & $21.5 \times 10^{-9}$ \\
\hline$M(46 \%)+I(54 \%)$ & DPG & 42 & $\operatorname{MEKP}(1.5 \%)+$ Co Oct $(0.5 \%)$ & 30 & $11.7 \times 10^{-9}$ \\
\hline$M(46 \%)+I(54 \%)$ & DPG & 42 & $\operatorname{MEKP}(1.5 \%)+\operatorname{Co}$ Oct $(0.5 \%)$ & 40 & $16.5 \times 10^{-9}$ \\
\hline$M(46 \%)+\mathrm{I}(54 \%)$ & DPG & 42 & $\operatorname{MEKP}(1.5 \%)+\operatorname{Co}$ Oct $(0.5 \%)$ & 50 & $23 \times 10^{-9}$ \\
\hline$M(46 \%)+I(54 \%)$ & PG & 43 & $\operatorname{MEKP}(1.5 \%)+\operatorname{Co}$ Oct $(0.5 \%)$ & 30 & $12.5 \times 10^{-9}$ \\
\hline$M(46 \%)+I(54 \%)$ & PG & 43 & $\operatorname{MEKP}(1.5 \%)+$ Co Oct $(0.5 \%)$ & 40 & $16 \times 10^{-9}$ \\
\hline$M(46 \%)+I(54 \%)$ & PG & 43 & $\operatorname{MEKP}(1.5 \%)+$ Co Oct $(0.5 \%)$ & 50 & $24.5 \times 10^{-9}$ \\
\hline
\end{tabular}

Fick's law is based on the assumption that diffusivity does not change with the penetrant concentration. However, a concentration-dependent diffusivity was observed [30] as depicted in Fig. 9.7 showing unambiguously the existence of a non-Fickian process; since the plot of relative mass uptake does not intersect a 0 for $t=0$, and the water diffusivity depends on its concentration which was mathematically modeled as:

$$
D=D_{0} \times \exp (\gamma \times c)
$$

where $\gamma$ is a plastification coefficient describing the fact that the sorption of the penetrant increases free volume in the matrix which facilitates its diffusion. A complete investigation by Marais et al. [30] shows that $D$ is multiplied by about 3 when water activity increases from 0.2 to 1 (Fig. 9.7).

In conclusion, water diffusion in UPR seems to be Fickian at first, but the finest investigations (featuring tests under several water activities) suggest a more complex mechanism for water diffusion. This remains to be linked with the structure of UPR. 


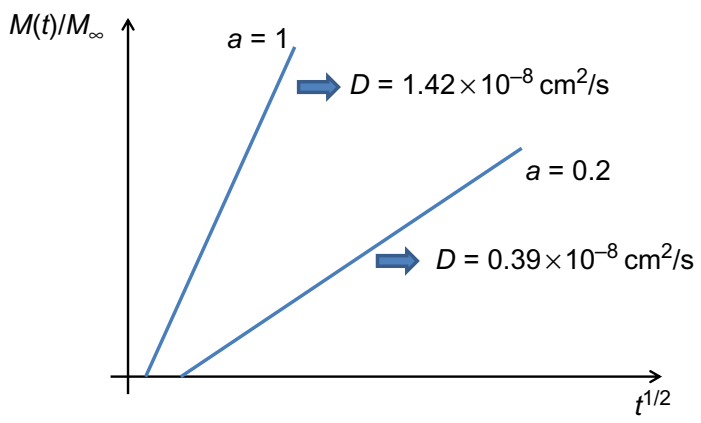

FIGURE 9.7

Plot of relative mass versus square root of the time for UP at $25^{\circ} \mathrm{C}$.

Table 9.5 Several Aging Modes and Their Consequences at Macromolecular Level

\begin{tabular}{|l|l|l|l|l|} 
& Hydrolysis & $\begin{array}{l}\text { Thermal } \\
\text { Oxidation }\end{array}$ & $\begin{array}{l}\text { Radio } \\
\text { Oxidation }\end{array}$ & $\begin{array}{l}\text { Photolysis and } \\
\text { Photooxidation }\end{array}$ \\
$\begin{array}{l}\text { Chain scission } \\
\text { Cross-linking }\end{array}$ & + & + & + & + \\
& 0 & $\begin{array}{l}\text { Post } \\
\text { polymerization }\end{array}$ & $\begin{array}{l}\text { Post polymerization, irradiation under } \\
\text { vacuum or of thick materials }\end{array}$ \\
\hline
\end{tabular}

\subsection{MECHANISMS OF CHEMICAL DEGRADATION}

\subsubsection{HYDROLYSIS}

As previously discussed, it was observed that:

- the interaction of UPRs with water leads first to a weight increase corresponding to water absorption, but later a mass decrease is observed corresponding to the leaching of small molecules even in fully cured matrices [17].

- UPRs display a strong drop in their mechanical properties in the presence of gaseous ethanol at $90^{\circ} \mathrm{C}$ or $115^{\circ} \mathrm{C}$ [8], whereas ethanol is only poorly soluble in UP.

The main reason is the existence of chemical damage (chain scission reactions-Table 9.5) overlapping with the physical damage (plastification of the network by the absorbed fluid). The rate of chain scissions formation is, in principle, given by:

$$
\frac{d s}{d t}=k \times\left(E_{0}-s\right) \times w
$$

where $k$ is the rate constant of hydrolysis, $E_{0}$ the initial concentration of hydrolysable groups (esters), $w$ the water concentration, and $s$ the concentration of chain scissions. 
Eq. (9.25) can be integrated as:

$$
s=E_{0} \times[1-\exp (-k \times w \times t)]
$$

And simplified as:

$$
s \sim k_{0} \times E_{0} \times w \times t
$$

Hence, it seems possible, in principle, to predict the rate of degradation from relatively simple data: water affinity, concentration of esters (depending on the structure of prepolymer and styrene content), and rate constant of prepolymer hydrolysis. This simplified approach only gives a rough estimation of degradation since there are many complications including either chemical: (1) copolymer effect, (2) autocatalytic effects, (3) chain end effects, or physical factors: (4) changes in hydrophilicity with aging conversion degree, (5) effects linked to water diffusion.

1. The copolymer effect: the hydrolysis rate constant in UP made of phtalate and maleate/fumarate is observed to differ from values observed in corresponding pure phthalate or maleate/fumarate UPs due to ester-ester interactions or hindrance by styrene [34].

2. Autocatalytic effects: Hydrolysis generates a carboxylic acid which can act as a catalyst of further hydrolysis events. The differential system becomes [47]:

$$
\frac{d s}{d t}=k_{0} \times\left(E_{0}-s\right) \times w+k_{\text {cat }} \times\left(E_{0}-s\right) \times s \times w
$$

Some examples of the autocatalytic hydrolysis of polyester-based polymers can be found in Refs. [46,48], but the case of UPR has not been investigated.

3. The chain ends are possibly more reactive than constitutive units located in the middle of chains [14] (Scheme 9.1).
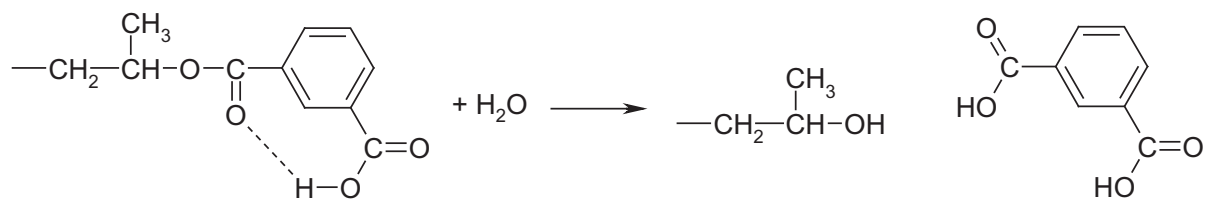

\section{SCHEME 9.1}

Self-decomposition of chain ends in UPR.

4. Changes in water affinity induced by hydrolysis: esters (being moderately polar) are converted into much more hydrophilic species (carboxylic acid, alcohol). It is, hence, possible that water equilibrium uptake is expressed as [14]:

$$
w=w_{0}+a \times s
$$

where $s$ expresses the number of hydrolysis events. The systematic study of hydrolysis (or even aging) induced changes in water affinity remains, however, scarcely studied.

5. Water diffusion effects: water is submitted to competition between the reactions of hydrolysis and diffusion from the surface layers to deeper layers. This results in the existence of a degraded layer, the thickness of which can be approximated by [14]:

$$
z^{2}=\frac{D_{w}}{k[w]}
$$




\begin{tabular}{|c|c|c|c|c|}
\hline $\begin{array}{l}\text { Aging } \\
\text { Mode }\end{array}$ & $\begin{array}{l}\text { Experimental } \\
\text { Conditions }\end{array}$ & \multicolumn{2}{|c|}{ Kinetic Parameters } & $\begin{array}{l}z_{\text {degraded }} \\
(\mu \mathrm{m})\end{array}$ \\
\hline Hydrolysis & $100^{\circ} \mathrm{C}-100 \% \mathrm{HR}$ & $\begin{array}{l}D_{\mathrm{w}}=(6 \pm 1) \times 10^{-11} \mathrm{~m}^{2} / \mathrm{s} \\
k^{\prime}=(4-30) \times 10^{-7} \mathrm{~s}^{-1}\end{array}$ & $\begin{array}{l}E_{\mathrm{Dw}}=25-30 \mathrm{~kJ} / \mathrm{mol} \\
\text { (Table } 9.4 \text { ) } \\
E_{\mathrm{H}}=65 \mathrm{~kJ} / \mathrm{mol}[47]\end{array}$ & $450-1200$ \\
\hline Photoaging & $\begin{array}{l}60^{\circ} \mathrm{C}-\mathrm{SEPAP} \\
12-24\end{array}$ & & $\begin{array}{l}E_{\mathrm{DO} 2}=20-45 \mathrm{~kJ} / \mathrm{mol} \\
\text { (Table } 9.7 \text { ) }\end{array}$ & 140 \\
\hline $\begin{array}{l}\text { Thermal } \\
\text { aging }\end{array}$ & $160^{\circ} \mathrm{C}$ & & $E_{\mathrm{OX}}=50 \mathrm{~kJ} / \mathrm{mol}[58]$ & 600 \\
\hline
\end{tabular}

Since water solubility hardly depends on temperature, the thickness of this degraded layer depends on temperature:

$$
E_{\mathrm{z}}=1 / 2\left(E_{\mathrm{D}}-E_{\mathrm{k}}\right)
$$

It is well documented that $E_{\mathrm{D}}<E_{\mathrm{k}}$ so the thickness of the degraded layer measured at elevated temperature (during an accelerated aging test) is quite different from the value observed in "service" conditions. Such diffusion-reaction coupling can be predicted using numerical models $[49,50]$. Some experimental values (for hydrolytic aging together with other aging modes) are given in Table 9.6.

In terms of structure-properties relationships, existing data show that maleates and fumarates are more unstable than isophthalates and orthophthalates because of higher hydrolysis rate constants and higher hydrophilicity. Generally, isophthalates induce a higher stability than orthophthalates [51,52]. Neopentyl glycol induces a higher stability than propylene glycol [52,53] and ethylene glycol-based polyesters are also quite unstable [34].

As hydrolysis at moderate temperatures (typically below UPR-glass transition) is an aging mode leading to polymer failure, there is an increasing interest in using hydrolysis as a recycling mode for UPR networks by regenerating feedstock (in particular the diol). Subcritical water (with the use of strong alkali: $\mathrm{NaOH}$ or $\mathrm{KOH}$ ) can potentially allow for the recovery of a great part of glycol after a treatment at $230^{\circ} \mathrm{C}$ for 1 hour [54]. There are, however, some complexities linked to high temperature hydrolysis in the presence of additives ( $\mathrm{KOH}$, phenol) in UPR where secondary reactions (typically above $200^{\circ} \mathrm{C}$ ) can generate a wide variety of chemicals [55].

\subsubsection{THERMAL AGING}

Thermal degradation is a radical in chain mechanism. At relatively high temperatures $\left(>200^{\circ} \mathrm{C}\right)$, the thermolysis of the polymer backbone is by far the main source of radicals, whereas at "moderate" temperatures $\left(<150^{\circ} \mathrm{C}\right.$, i.e., in UPR service conditions $)$, the thermal decomposition of hydroperoxides becomes kinetically prominent.

In the case of thermal degradation at high temperatures, a kinetic analysis of nonisothermal degradation curves suggested that degradation first occurs on styrene groups [56] in good agreement with the analysis of volatiles [57].

The case of thermal aging of UPRs at moderate temperatures (at which the main source of radical generation is hydroperoxides) is in part different. In the case of thermal aging of polyester 
monitored by FTIR, Arrieta et al. [58] observed that the main chemical change was the formation of an anhydride (Fig. 9.8). Their interpretation was that anhydrides are formed by the oxidation of methylene in the $\alpha$-position of the ester group. They confirmed their reasoning from analysis of a thermally oxidized prepolymer (where anhydrides were also observed) and from the absence of acetophenone groups characteristic of polystyrene oxidation [59].

The most plausible mechanism is based on the radical attack of $\mathrm{C}-\mathrm{H}$ in the $\alpha$-position of the ester groups. The main consequences of this mechanism are the formation of anhydride and some chain scissions (Scheme 9.2).

(A)

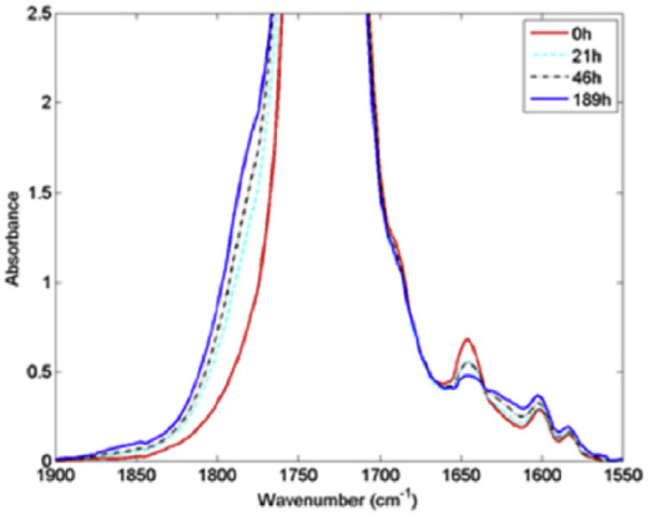

(B)

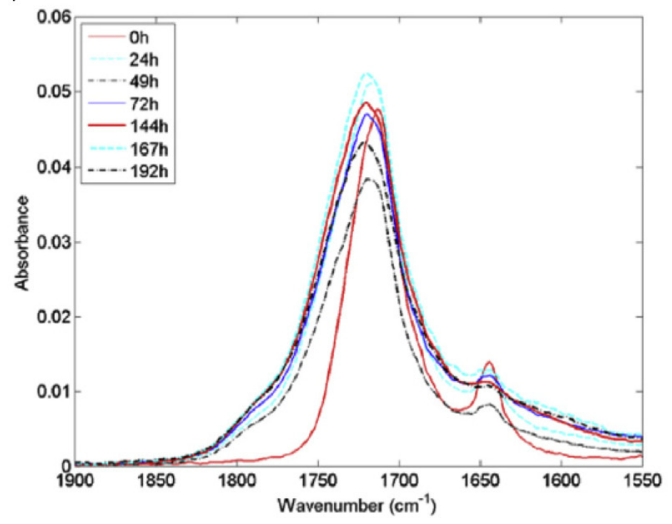

FIGURE 9.8

FTIR spectra of a UPR (A) and its prepolymer (B) thermally oxidized at $160^{\circ} \mathrm{C}$ [58].

Reprinted with the permission of Elsevier.
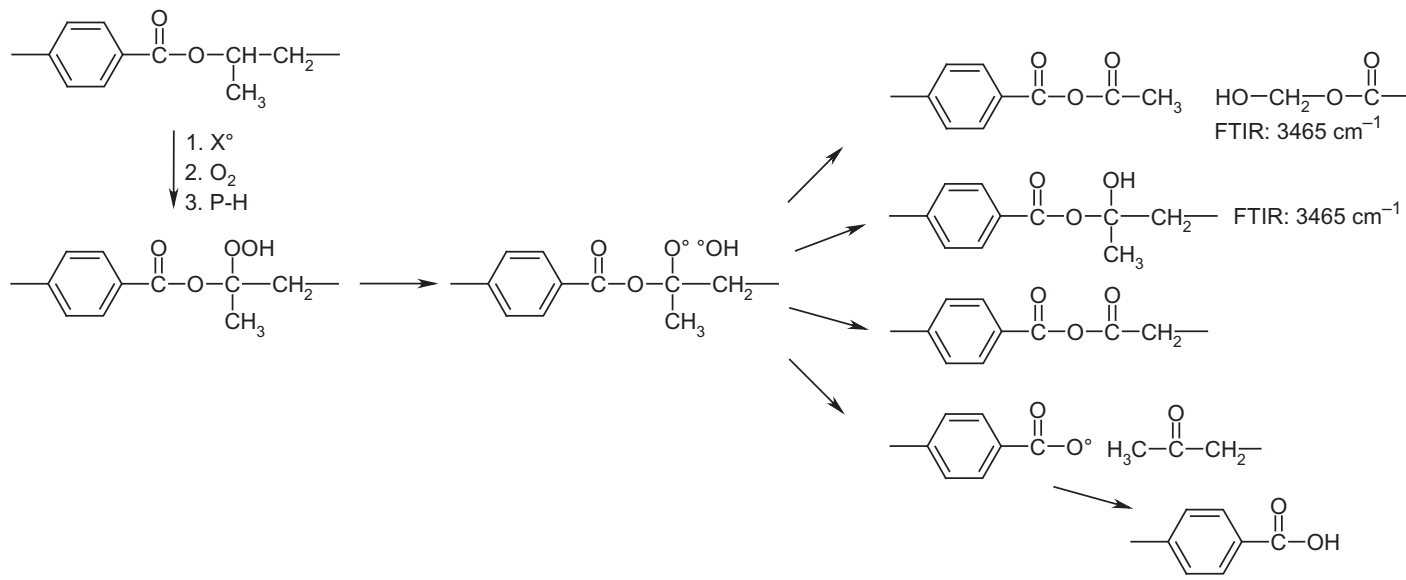

FTIR: 1690 and $3300 \mathrm{~cm}^{-1}$ 
Another consequence of thermal aging at high temperatures is the high yield of volatiles resulting from advanced chain scission processes (Table 9.4). According to Arrieta et al. [58], they can occur even under an inert atmosphere (i.e., from the direct thermolysis of the polymer), but are strongly accelerated by oxygen (Fig. 9.9).

Shih et al. [57] studied the high temperature thermal degradation of epoxy-polyester IPNs. According to their results:

- Modulated thermogravimetric analysis (TGA) curves can permit the extraction of kinetic parameters of apparent kinetic models for nonisothermal degradation. It seems that epoxy allows for the thermal stability of UPR and IPNs to be improved, which later display kinetic parameters in between those of UPR and epoxies. The authors, however, stated that the degradation of UPR and epoxy in IPNs do not interfere.

- Pyrolysis tests followed by GC/MS for thermal degradation at relatively high temperature analysis reveal that almost the same degradation products are evolved from IPNs and epoxies (mainly bisphenol-A, isopropenyl phenol, and phenol), whereas the products characterizing the thermal degradation of polyesters (in particular styrene monomers, dimers, and even trimers) are absent. Those two results can be considered as somewhat difficult to reconcile. The durability of IPNs thus appears to be an open issue.

Identically to hydrolytic aging, a degraded layer is generated [60] due to a diffusion-reaction coupling as schematized in Fig. 9.10.

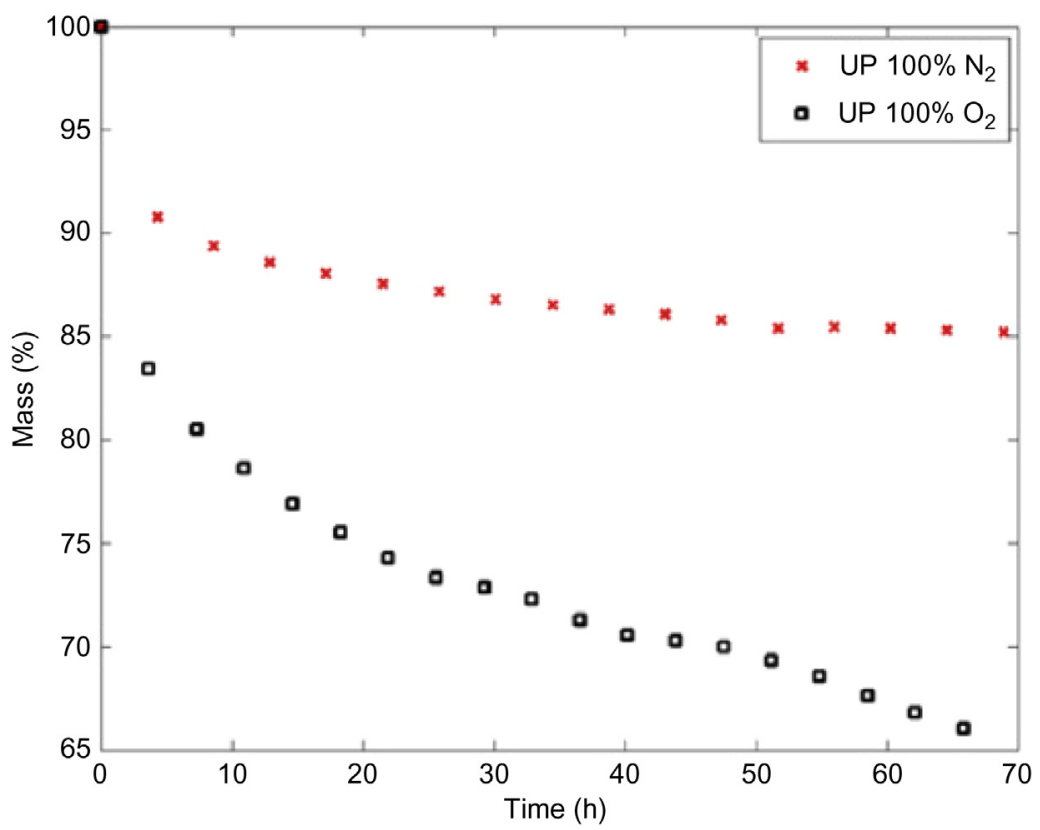

FIGURE 9.9

Kinetic curves for mass loss for a UP network thermally aged at $160^{\circ} \mathrm{C}$ [58]. 


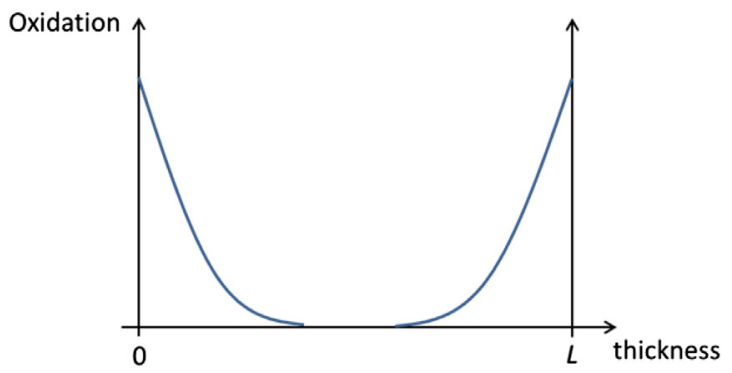

FIGURE 9.10

Degradation profile of oxidized materials (NB: $x=0$ and $x=L$ correspond to edges in contact with atmospheric air).

Its thickness can be approximated by $[61,62]$ :

$$
\mathrm{TOL}^{2}=\frac{D_{\mathrm{O}_{2}} \times\left[\mathrm{O}_{2}\right]}{r_{\mathrm{OX}}}
$$

where $r_{\mathrm{OX}}$ is the oxidation rate on the surface of polymer, $D_{\mathrm{O}_{2}}$ and $\left[\mathrm{O}_{2}\right]$ are the oxygen diffusivity and concentration in a given polymer matrix, respectively. It is hence crucial to determine the oxygen transport properties in UP matrices. Some values as reported by Pauly [63] are presented in Table 9.7.

\subsubsection{RADIOLYTIC AGING}

The effect of irradiation on UPs was described by Wilski [64] in the case of high-dose irradiation under an inert atmosphere, and lower dose irradiation under air.

The results unambiguously show competition between two phenomena. The first one occurs in the absence of oxygen and results in an increase (at least in the earliest exposure doses, i.e., lower than $1 \mathrm{MGy}$ ) of thermomechanical properties (deflection temperature being linked to $T_{\mathrm{g}}$, flexural and impact strengths). The second one is favored by the presence of oxygen and induces the depletion of the mentioned properties (Fig. 9.11).

The most reasonable explanation is common with other polymers and is based on the existence of a degraded layer as developed in Section 9.4.2.

(1) Under nitrogen (or in the bulk of thick materials where aging mechanisms are anaerobic), irradiation generates radicals reacting by coupling (cross-linking):

$$
\begin{gathered}
\text { Polymer }+h \nu \rightarrow \mathrm{P}^{\circ}+1 / 2 \mathrm{H}_{2} \\
\mathrm{P}^{\circ}+\mathrm{P}^{\prime} H \rightarrow \mathrm{PH}+\mathrm{P}^{\circ} \\
\mathrm{P}^{\circ}+\mathrm{P}^{\circ} \rightarrow \mathrm{PH}+\text { double bond (dismutation) } \\
\mathrm{P}^{\circ}+\mathrm{P}^{\circ} \rightarrow \mathrm{P}-\mathrm{P} \text { (cross-linking) }
\end{gathered}
$$

This supplementary radiation induced cross-linking improves the mechanical properties as observed by Charlesby et al. [65] in the case of the radio-curing of UPR. 


\begin{tabular}{|c|c|c|c|c|c|c|c|c|c|}
\hline \multicolumn{2}{|c|}{ Main Components (\%) } & \multirow{2}{*}{$\begin{array}{l}\text { Sample } \\
\text { Thickness (cm) } \\
0.2\end{array}$} & \multirow{2}{*}{$\begin{array}{l}\boldsymbol{T}\left({ }^{\circ} \mathbf{C}\right) \\
23\end{array}$} & \multirow{2}{*}{$\begin{array}{l}\mathbf{1 0}^{\mathbf{1 5}} \times \mathbf{P} \\
1.04\end{array}$} & \multirow{2}{*}{$\begin{array}{l}\mathbf{1 0} \mathbf{8}^{\mathbf{x}} \times \mathrm{D} \\
0.57\end{array}$} & \multirow{2}{*}{$\begin{array}{l}\boldsymbol{E}_{\mathbf{D}}(\mathbf{k J} / \mathbf{m o l}) \\
35\end{array}$} & $10^{7} . S$ & \multirow{2}{*}{ 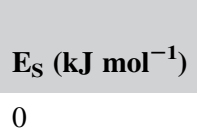 } & \multirow{2}{*}{$\begin{array}{l}\text { Refs. } \\
{[63]}\end{array}$} \\
\hline UP resin & 25 & & & & & & 1.82 & & \\
\hline Limestone & 52.7 & & 40 & 2.24 & 1.26 & & 1.78 & & \\
\hline Short GF & 15 & & 60 & 5.21 & 2.77 & & 1.88 & & \\
\hline UP resin & 26 & 0.18 & 23 & 3.08 & 1.03 & 45 & 3 & -1 & {$[63]$} \\
\hline Limestone & 26 & & 40 & 7 & 2.8 & & 2.5 & & \\
\hline China clay & 38.3 & & 60 & 17 & 8 & & 2.13 & & \\
\hline Up resin & 100 & 0.02 & 25 & 0.66 & 3.6 & 20.8 & 0.18 & * & {$[58]$} \\
\hline & & & 100 & 2.34 & 19.5 & & 0.12 & & \\
\hline Up resin & 32 & 0.02 & 25 & 0.29 & 2.3 & 21.6 & 0.13 & $*$ & {$[58]$} \\
\hline ATH $+\mathrm{Zn}$ Borate & 68 & & 100 & 2.36 & 13.3 & & 0.18 & & \\
\hline
\end{tabular}




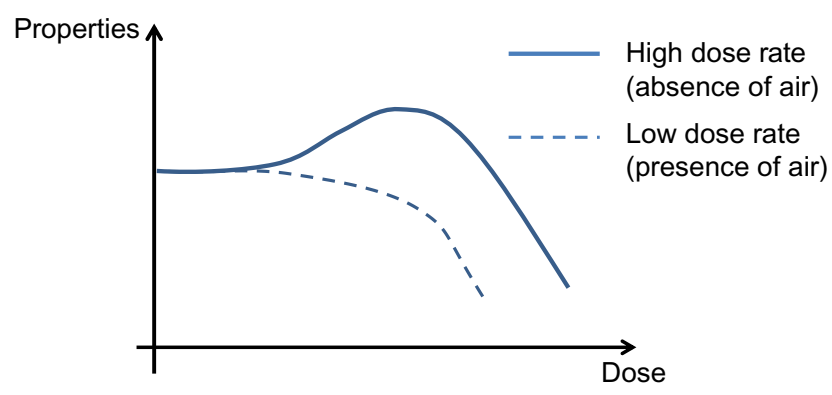

FIGURE 9.11

Properties of unsaturated polyester during irradiation [64].

(2) In the presence of oxygen (or in the oxidized layer of bulk materials), alkyl radicals react with oxygen and lead to peroxyl radicals and later hydroperoxides; the decomposition of which generating several products among which are chain scissions:

$$
\begin{gathered}
\mathrm{P}^{\circ}+\mathrm{O}_{2} \rightarrow \mathrm{POO}^{\circ} \\
\mathrm{POO}^{\circ}+\mathrm{PH} \rightarrow \mathrm{POOH}+\mathrm{P}^{\circ} \\
\mathrm{POOH} \rightarrow \mathrm{PO}^{\circ}+\mathrm{HO}^{\circ} \\
\mathrm{PO}^{\circ} \rightarrow \mathrm{P}=\mathrm{O}+\text { chain scissions }
\end{gathered}
$$

In the case of the irradiation of thick UPR materials, both phenomena can simultaneously occur; their relative proportion depending on the depth in the irradiated polymer.

Another reason for the heterogeneity in irradiated polymers is the attenuation of irradiation in the thickness:

$$
\frac{I}{I_{0}}=\exp (-\mu \times z)
$$

where $I_{0}$ is the initial intensity of $\gamma$-ray, $I$ is the intensity of the ray transmitted from a shielding material of thickness $x$, and $\mu$ is the linear attenuation coefficient.

It was observed that the use of lead monoxide particles (with a weight fraction of about 5\%) made possible the attenuation of a coefficient comparable to concrete for Cs-137 or Ir-192 sources, but that even highly filled (more than 30\%) UPRs could not efficiently shield Co-60 radiations [66].

\subsubsection{PHOTOAGING}

Polyesters are reported to undergo photolytic processes such as the conversion of fumarates into maleates, the dimerization and decomposition of maleates (Scheme 9.3) [67], and the photocleavage of esters (Scheme 9.4) [68]:

Photoaging also induces an in-chain radical oxidation mechanism, but in which radicals mainly come from some side reactions of radicals (such as those created in Scheme 9.4) and the decomposition of peroxides and hydroperoxides.

The relative rate of photolytic and photooxidation processes depends on the temperature, nature, and intensity of the spectral source, on the molar absorptivity of compounds (and subsequently the 
<smiles>COC(=O)/C=C/C(=O)OC</smiles>

FTIR: $1646 \mathrm{~cm}^{-1}$
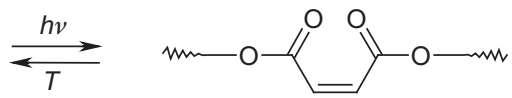

FTIR: $1641 \mathrm{~cm}^{-1}$

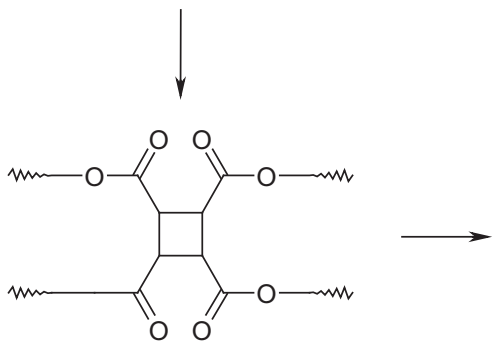

FTIR: $1754 \mathrm{~cm}^{-1}$

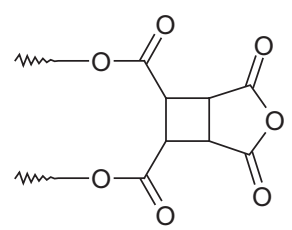

FTIR: 1735 and $1788 \mathrm{~cm}^{-1}$

\section{SCHEME 9.3}

Mechanisms of photoisomerization and photodimerization of fumarate units.

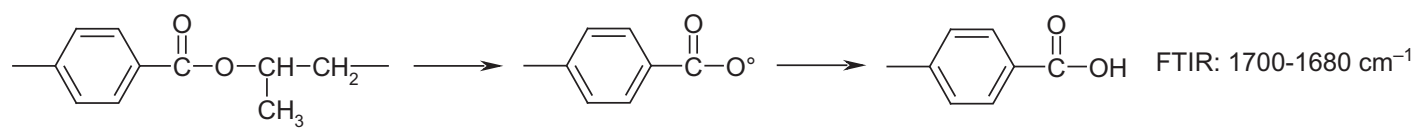<smiles>CC=CC(=O)OC(C)CCCC=CC(=O)[O-]</smiles>

\section{SCHEME 9.4}

Mechanism of photocleavage of polyesters.

thickness of material) [69], and on the presence of oxygen. For example, according to [70], phthalates and fumarate/maleate groups are responsible for absorption at long wavelength $(>300 \mathrm{~nm})$, whereas the photooxidation at short wavelength might involve $S$ units as well [71]. In summary:

- radicals are created either from the photolysis of an impurity or of hydroperoxides and ketones:

$$
\begin{gathered}
\mathrm{X} \rightarrow \mathrm{P}^{\circ} \\
\mathrm{POOH} \rightarrow \mathrm{PO}^{\circ}+\mathrm{HO}^{\circ} \rightarrow 2 \mathrm{P}^{\circ}+\text { carbonyls }
\end{gathered}
$$

- they propagate to regenerate hydroperoxides:

$$
\begin{gathered}
\mathrm{P}^{\circ}+\mathrm{O}_{2} \rightarrow \mathrm{POO}^{\circ} \\
\mathrm{POO}^{\circ}+\mathrm{PH} \rightarrow \mathrm{POOH}+\mathrm{P}^{\circ}
\end{gathered}
$$


- several termination mechanisms can coexist depending on the concentration of oxygen [72]:

$$
\begin{gathered}
\mathrm{P}^{\circ}+\mathrm{P}^{\circ} \rightarrow \text { inactive products } \\
\mathrm{P}^{\circ}+\mathrm{POO}^{\circ} \rightarrow \text { inactive products } \\
\mathrm{POO}^{\circ}+\mathrm{POO}^{\circ} \rightarrow \text { inactive products }
\end{gathered}
$$

In UPRs, several reactive sites are suspected to be involved. The appearance of yellowing products absorbing at $295-400 \mathrm{~nm}$ (similarly to polystyrene) led Michaille et al. [67] to propose a photooxidation mechanism in which styrene units are the main oxidation site (Scheme 9.5).

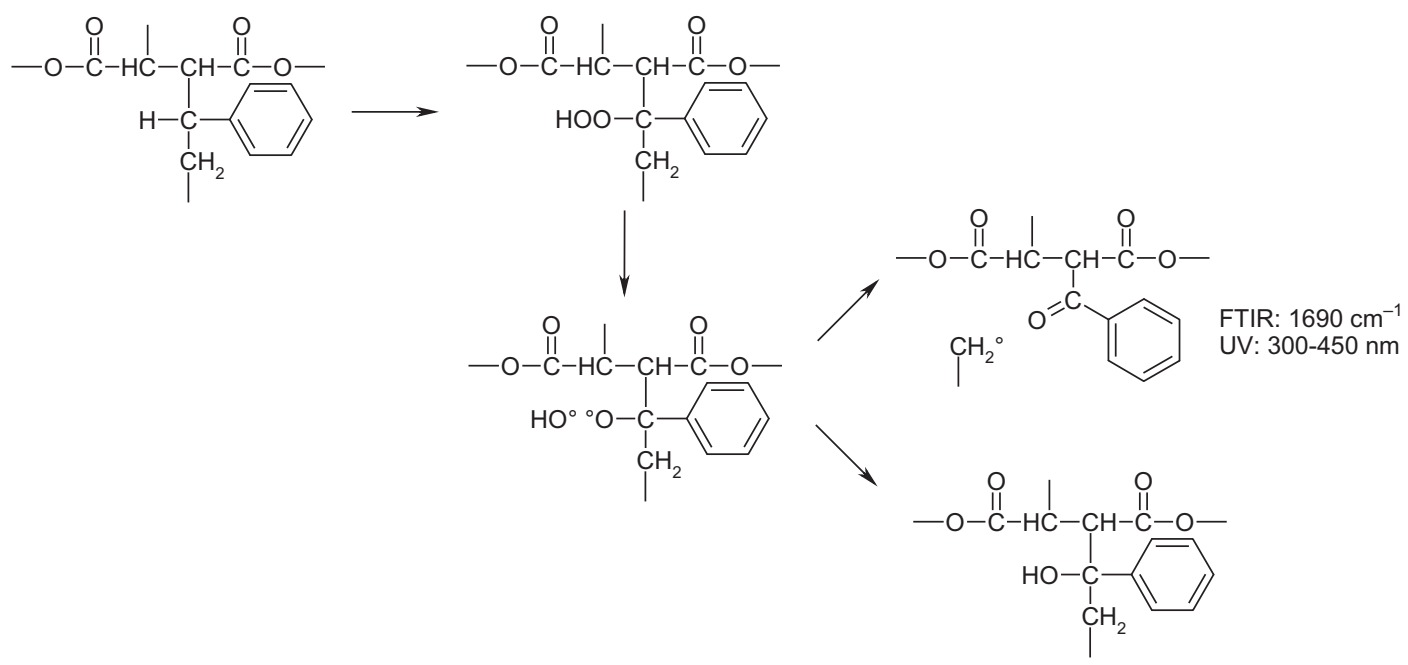

\section{SCHEME 9.5}

Mechanism of radical oxidation of styrene in unsaturated polyester resin (UPR).

Polyester prepolymer can also undergo radical attack depending on the concentration of styrene as a cross-linking agent [67]. In other words, the tertiary $\mathrm{C}-\mathrm{H}$ group of $\mathrm{S}$ units would be more oxidizable than poly(propylene glycol maleate) or poly(propylene glycol isophthalate), but at a low styrene concentration, these later become the predominant sites of propagation. A part of this "duality" can be explained from the relative kinetics of propagation:

$$
\begin{array}{ll}
\mathrm{P}_{1} \mathrm{OO}^{\circ}+\mathrm{P}_{1} \mathrm{H} \rightarrow \mathrm{P}_{1} \mathrm{OOH}+\mathrm{P}_{1}{ }^{\circ} & r_{11} \\
\mathrm{P}_{1} \mathrm{OO}^{\circ}+\mathrm{P}_{2} \mathrm{H} \rightarrow \mathrm{P}_{1} \mathrm{OOH}+\mathrm{P}_{2}{ }^{\circ} & r_{12} \\
\mathrm{P}_{2} \mathrm{OO}^{\circ}+\mathrm{P}_{1} \mathrm{H} \rightarrow \mathrm{P}_{2} \mathrm{OOH}+\mathrm{P}_{1}{ }^{\circ} & r_{21} \\
\mathrm{P}_{2} \mathrm{OO}^{\circ}+\mathrm{P}_{2} \mathrm{H} \rightarrow \mathrm{P}_{2} \mathrm{OOH}+\mathrm{P}_{2}{ }^{\circ} & r_{22}
\end{array}
$$

Here 1 would correspond to styrene units and 2 to prepolymer units. The relative rates of propagation would be:

$$
\frac{r_{11}}{r_{12}}=\frac{k_{11}\left[\mathrm{P}_{1} \mathrm{H}\right]}{k_{12}\left[\mathrm{P}_{2} \mathrm{H}\right]}
$$


There are some relationships linking structure and sensitivity to oxidation according to which [73]:

$$
\begin{gathered}
\log k_{i j}\left(30^{\circ} \mathrm{C}\right)=16.2-0.0477 \times \mathrm{BDE}_{j} \\
E_{i j}=0.55 \times\left(\mathrm{BDE}_{j}-262\right)
\end{gathered}
$$

if $i$ is a secondary peroxyl radical and $j$ the broken $\mathrm{C}-\mathrm{H}$. While,

$$
\begin{gathered}
\log k_{i j}\left(30^{\circ} \mathrm{C}\right)=15.2-0.0477 \times \mathrm{BDE}_{j} \\
E_{i j}=0.55 \times\left(\mathrm{BDE}_{j}-262\right)
\end{gathered}
$$

if $i$ is a tertiary peroxyl radical.

One can easily verify that:

- the competition between each propagation reaction depends on the concentration of the reactive sites (propylene glycol or styrene), and

- using reasonable values of BDE (375 for $\mathrm{S} \mathrm{C}-\mathrm{H}, 395 \mathrm{~kJ} / \mathrm{mol}$ for propylene glycol ones), propagation rate constants can cross, that is, that $k_{312}>k_{321}$ at moderate temperatures and $k_{321}$ $>k_{312}$ at higher temperatures.

In other words, it can be concluded that the oxidative degradation of UPR must be described by a cooxidation model [74], which requires a complex stage of kinetic parameters estimation.

Those equations linking reactivity (the rate constant) with structure (the bond dissociation energy) also permit for the confirmation of why neopentyl glycol permits a decrease in the oxidation effects compared to propylene glycol [70] because of the absence of tertiary (weak) $\mathrm{C}-\mathrm{H}$ bonds.

One of the most undesired consequences of photoaging and photooxidation is the yellowing of the material. Several processes might be responsible including:

1. Photolytic processes (i.e., occurring without oxygen) can induce a strong change in the aspect of UP materials, featuring gloss, and color changes. Michaille et al. [70] pointed out that the photolysis of phthalate is identical to that observed in the photolysis of polybutylene terephthalate (PBT) [75] (Scheme 9.6).

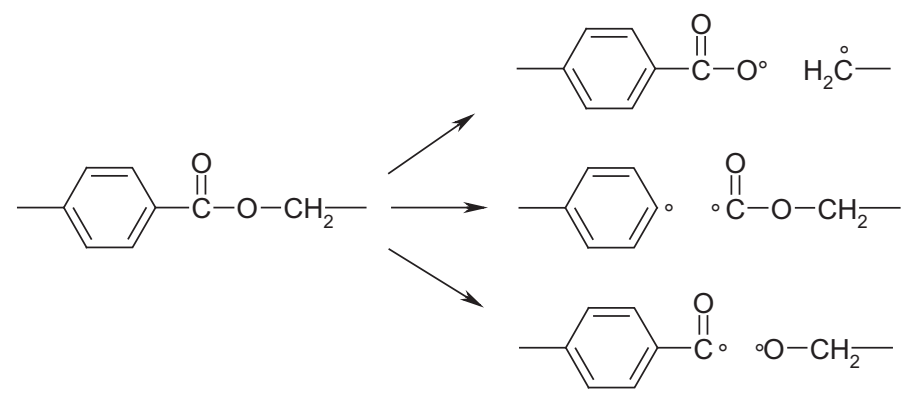

\section{SCHEME 9.6}

Mechanism of photodissociation. 
Then radicals recombine to give several kinds of benzophenones responsible for yellowing:

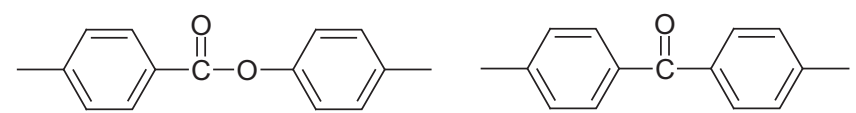

The work of Geuskens also revealed the role of polyenes formed during the photolysis of polystyrene absorbing at $280-450 \mathrm{~nm}[71]$ :

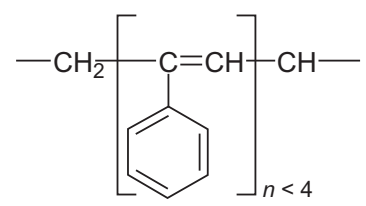

2. Under oxygen, radicals formed in $\mathrm{S}$ units can react with oxygen and generate benzalacetophenone (Scheme 9.7) or $\alpha-\beta$-unsaturated ketone (Scheme 9.8).

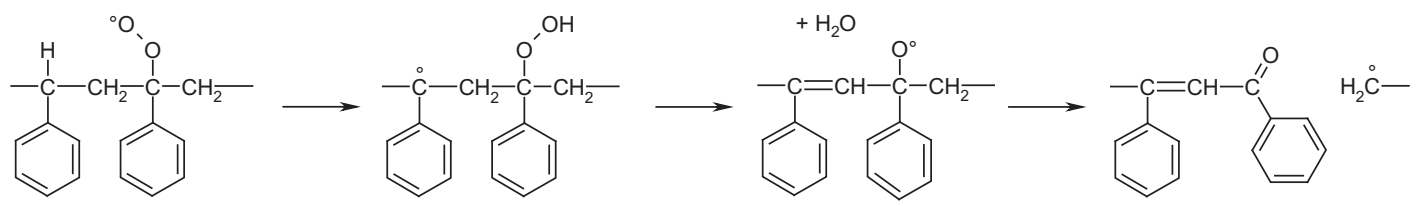

\section{SCHEME 9.7}

Formation of benzalacetophenone.<smiles>[Y][R6]([H])([H])CCC(CC(CC(C)c1ccccc1)c1ccccc1)c1ccccc1</smiles><smiles>C=C(CC(CCC)c1ccccc1)CC(CCC)c1ccccc1</smiles>

\section{SCHEME 9.8}

Formation of $\alpha-\beta$-unsaturated ketone.

According to Sampers [76], it seems that:

- yellowing is, in particular, caused by interactions between UV radiations below $360 \mathrm{~nm}$ displaying a strong absorption with the prepolymer itself (meanwhile polystyrene sequences and some cobalt accelerator seem to display a very limited absorption). 
- color changes seem to be driven rather by the photolysis of the polyester sequences compared to styrene unit sequences where the effect of oxygen is relatively limited. The oxidation of structures formed by photolysis results in less absorbent groups.

Identically to thermal and radiolytic aging, the photochemical degradation of UPR is accompanied by the formation of an oxidized layer. Interestingly, the thermal degradation of UP is characterized by a lower oxidation rate than photochemical one so that the thickness of the oxidized layer was observed to be about $600 \mu \mathrm{m}$ for thermal oxidation at $160^{\circ} \mathrm{C}$ versus only $140 \mu \mathrm{m}$ in the case of photooxidized UP (despite the fact that photochemical aging is performed at lower temperatures than thermal aging).

It has been observed that photodegraded UPR can undergo cross-linking [70]. Several mechanisms are responsible including

the dimerization of phthalate units (similarly to PBT photolysis under vacuum [75]) and the double bond opening of unsaturated structures formed by the photolysis of S units (Scheme 9.9):<smiles>COC(=O)c1ccc(C(=O)OC)c(-c2cc(C(=O)OC)ccc2C(=O)OC)c1</smiles>

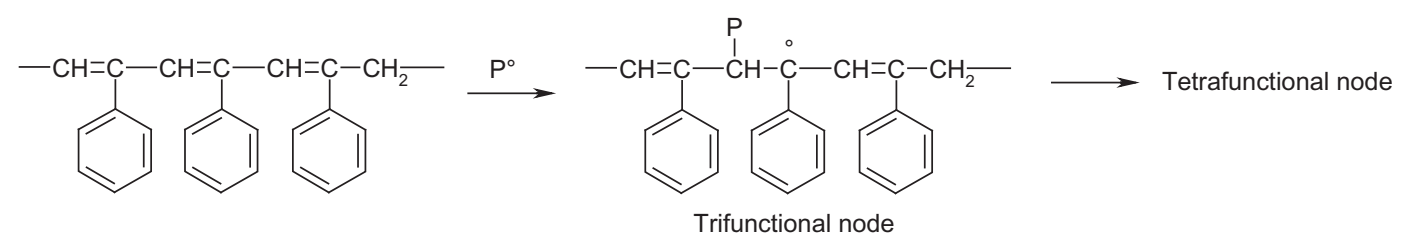

\section{SCHEME 9.9}

A possible mechanism of cross-linking.

\subsection{CONCLUSION}

This chapter described the aging mechanisms of UP-based materials. Degradation mechanisms were first addressed from the structure-properties involved to describe the consequences of aging on mechanical properties.

Physical aging mechanisms were presented. UPs are sensitive to some chemicals, but engineers have at their disposal rules for predicting compatibility and avoiding undesirable permeation effects. Water is, in essence, poorly soluble in UPs but its diffusion is accompanied by the hydrolysis of ester groups which is an an aggravating factor. 
Chemical mechanisms (hydrolytic, radiochemical, photochemical, and thermal) were thus presented together with some models predicting the rate of hydrolysis or the thickness of degraded layers, etc.). The main complexity for implementing them is the nonideal structure of UP where several reactive sites exist and whose reactivity depends on their chemical environment.

\section{REFERENCES}

[1] G.D. Jefferson, B. Farah, M.L. Hempowicz, K.-T. Hsiao, Influence of hygrothermal aging on carbon nanofiber enhanced polyester material systems, Comp. Part B: Eng. 78 (1) (2015) 319-323.

[2] J.-P. Pascault, H. Sautereau, J. Verdu, R.J.J. Williams, Thermosetting polymers, Effect of Crosslink Density on Elastic and Viscoelastic Properties., Marcel Dekker, 2002, pp. 323-348. Chap. 11.

[3] J.E. Mark, The rubber elastic state. Chap 1 in: J.E. Mark, A. Eisenberg, W.W. Graessley, L. Mandelkern, J.L. Koenig (Eds.), Physical Properties of Polymers, American Chemical Society, Washington, DC, 1984, pp. 1-54.

[4] J.P. Morales Arias, C. Bernal, A. Vázquez, M.M. Escobar, Aging in water and in an alkaline medium of unsaturated polyester and epoxy resins: experimental study and modeling, Polym. Adv. Technol. 37 (2) (2018) 450-460.

[5] G. Apolinario, P. Ienny, S. Corn, R. Léger, A. Bergeret, J.-M. Haudin, Effects of water ageing on the mechanical properties of flax and glass fibre composites: degradation and reversibility. ICNF $2015-$ 2nd International Conference on Natural Fibers, Apr 2015, Sao Miguel, Portugal, <hal-01255205>.

[6] L. Gautier, B. Mortaigne, V. Bellenger, J. Verdu, Osmotic cracking nucleation in hydrothermal-aged polyester matrix, Polymer. (Guildf). 41 (7) (2000) 2481-2490.

[7] S. Baek Lee, T.J. Rockett, R.D. Hoffman, Water-induced nucleation of disc cracks in selected thermosets, Polymer. (Guildf). 33 (11) (1992) 2353-2363.

[8] C. Barlette da Cunha, P. Pollizello Lopes, F. Dias Mayera, R. Hoffmann, Assessment of chemical and mechanical properties of polymers aiming to replace the stainless steel in distillation column, Mater. Res. <https://doi.org/10.1590/1980-5373-mr-2017-0679>.

[9] V. Bellenger, B. Mortaigne, M.F. Grenier-Loustalot, J. Verdu, Structure-property relationships for styrene crosslinked polyesters. I. Network structure and rubbery elastic modulus, J. Appl. Polym. Sci. 44 (1992) 643-651.

[10] E.A. DiMarzio, On the second-order transition of a rubber, J. Res. Natl. Bur.Stand. Sect. A 68 (1964) 611-617.

[11] V. Bellenger, J. Verdu, E. Morel, Effect of structure on glass transition temperature of amine crosslinked epoxies, J. Polym. Sci. Part B: Polym. Phys. 25 (6) (1987) 1219-1234.

[12] V. Bellenger, B. Mortaigne, J. Verdu, Structure-property relationships for styrene crosslinked polyesters. II. Glass transition temperature, J. Appl. Polym. Sci. 44 (4) (1992) 653-661.

[13] J.-P. Pascault, H. Sautereau, J. Verdu, R.J.J. Williams, Thermosetting polymers, Yielding and Fracture of Polymer Networks, Marcel Dekker, 2002, pp. 350-388. Chap 12.

[14] V. Bellenger, M. Ganem, B. Mortaigne, J. Verdu, Lifetime prediction in the hydrolytic ageing of polyesters, Polym. Degrad. Stability 49 (1) (1995) 91-97.

[15] A. Chateauminois, L. Vincent, B. Chabert, J.P. Soulier, Study of the interfacial degradation of a glass-epoxy composite during hygrothermal ageing using water diffusion measurements and dynamic mechanical thermal analysis, Polymer. (Guildf). 35 (22) (1994) 4766-4774.

[16] E. Faguaga, C.J. Pérez, N. Villarreal, E.S. Rodriguez, V. Alvarez, Effect of water absorption on the dynamic mechanical properties of composites used for windmill blades, Mater. Design 36 (2012) $609-616$. 
[17] L. Gautier, B. Mortaigne, V. Bellenger, Interface damage study of hydrothermally aged glass-fibrereinforced polyester composites, Comp. Sci. Technol. 59 (16) (1999) 2329-2337.

[18] H. Ishida, J.L. Koenig, A fourier-transform infrared spectroscopic study of the hydrolytic stability of silane coupling agents on E-glass fibers, J. Polym. Sci. Part B: Polym. Phys. 18 (9) (1980) 1931-1943.

[19] N. Deslandes, V. Bellenger, F. Jaffiol, J. Verdu, Solubility parameter of a polyester composite material, J. Appl. Polym. Sci. 69 (13) (1998) 2663-2671.

[20] S. Ajithkumar, N.K. Patel, S.S. Kansara, Sorption and diffusion of organic solvents through interpenetrating polymer networks (IPNs) based on polyurethane and unsaturated polyester, Eur. Polym. J. 36 (11) (2000) 2387-2393.

[21] S. Ajithkumar, N.K. Patel, S.S. Kansara, Sorption behaviour of interpenetrating polymer networks based on polyurethane and unsaturated polyester, Polym. Gels Networks 6 (2) (1998) 137-147.

[22] E. Baur, K. Ruhrberg, W. Woishnis, Unsaturated Polyester Resins, Chemical Resistance of Thermosets, William Andrew, 2018, pp. 62-505.

[23] L. Masaro, X.X. Zhu, Physical models of diffusion for polymer solutions, gels and solids, Prog. Polym. Sci. 24 (5) (1999) 731-775.

[24] N. Deslandes, V. Bellenger, F. Jaffiol, J. Verdu, Relationship between morphology and solvent interactions of a polyester composite material, Comp. Part A: Appl. Sci. Manuf. 29 (12) (1998) 1481-1487.

[25] A.-K. KhalafAllah, L.-S. Eldein, E.-A. Elradi, H.-S. Mandour, Chemical and other properties of unsaturated polyester under various environmental conditions, Int. J. Sci. Eng. Res. 7 (11) (2016) 1011-1019.

[26] Y. Jaya Vinse Ruban, S. Ginil Mon, D. Vetha Roy, Chemical resistance/thermal and mechanical properties of unsaturated polyester-based nanocomposites, Appl. Nanosci. 4 (2) (2014) 233-240.

[27] S. Marais, M. Metayer, M. Labbe, Water diffusion and permeability in unsaturated polyester resin films characterized by measurements performed with a water-specific permeameter: analysis of the transient permeation, J. Appl. Polym. Sci. 74 (14) (1999) 3380-3395.

[28] S.-B. Lee, T.J. Rockett, R.D. Hoffman, Interactions of water with unsaturated polyester, vinyl ester and acrylic resins, Polymer. (Guildf). 33 (17) (1992) 3691-3697.

[29] G. Capiel, J. Uicich, D. Fasce, P.E. Montemartini, Diffusion and hydrolysis effects during water aging on an epoxy-anhydride system, Polym. Degrad. Stability 153 (2018) 165-171.

[30] S. Marais, M. Métayer, T.Q. Nguyen, M. Labbé, L. Perrin, J.M. Saiter, Permeametric and microgravimetric studies of sorption and diffusion of water vapor in an unsaturated polyester, Polymer. (Guildf). 41 (7) (2000) 2667-2676.

[31] V. Bellenger, B. Mortaigne, J. Verdu, Water sorption in styrene crosslinked polyesters, J. Appl. Polym. Sci. 41 (5-6) (1990) 1225-1233.

[32] F. Bélan, V. Bellenger, B. Mortaigne, J. Verdu, Water swelling of polyester networks, Macromol. Symp. 93 (1) (1995) 81-88.

[33] E. Morel, V. Bellenger, J. Verdu, Structure-water absorption relationships for amine-cured epoxy resins, Polymer. (Guildf). 26 (11) (1985) 1719-1724.

[34] F. Bélan, V. Bellenger, B. Mortaigne, J. Verdu, Relationship between the structure and hydrolysis rate of unsaturated polyester prepolymers, Polym. Degrad. Stability 56 (3) (1997) 301-309.

[35] I. Merdas, F. Thominette, A. Tcharkhtchi, J. Verdu, Factors governing water absorption by composite matrices, Comp. Sci. Technol. 62 (4) (2002) 487-492.

[36] L. Garden, R.A. Pethrick, A dielectric study of water uptake in epoxy resin systems, J. Appl. Polym. Sci. 134 (16) (2017).

[37] A. De Nicola, A. Correa, G. Milano, P. La Manna, P. Musto, G. Mensitieri, et al., Local structure and dynamics of water absorbed in poly(ether imide): a hydrogen bonding anatomy, J. Phys. Chem. B 121 (14) (2017) 3162-3176.

[38] B.H. Zimm, J.L. Lundberg, Sorption of vapors by high polymers, J. Phys. Chem. 60 (1956) 425-428. 
[39] J.L. Lundberg, Clustering theory and vapor sorption by high polymers, J. Macromol. Sci. Part B 3 (1969) 693-710.

[40] C.J. Chirayil, J. Joy, L. Mathew, J. Koetz, S. Thomas, Nanofibril reinforced unsaturated polyester nanocomposites: morphology, mechanical and barrier properties, viscoelastic behavior and polymer chain confinement, Ind. Crops Products 56 (2014) 246-254.

[41] S. Das, Mechanical and water swelling properties of waste paper reinforced unsaturated polyester composites, Const. Build. Mater. 138 (2017) 469-478.

[42] C. Wolf, H. Angellier-Coussy, N. Gontard, F. Doghieri, V. Guillard, How the shape of fillers affects the barrier properties of polymer/non-porous particles nanocomposites: a review, J. Memb. Sci. 556 (2018) 393-418.

[43] V.C.A. Cruz, M.M.S. Nóbrega, W.P. da Silva, L.H. de Carvalho, A.G.B. de Lima, An experimental study of water absorption in polyester composites reinforced with macambira natural fiber, Mater. Sci. Eng. Technol. 42 (11) (2011) 979-984.

[44] I. Merdas, A. Tcharkhtchi, F. Thominette, J. Verdu, W. Cook, Water absorption by uncrosslinked polymers, networks and IPNs having medium to high polarity, Polymer. (Guildf). 43 (17) (2002) 4619-4625.

[45] J. Crank, The Mathematics of Diffusion, Clarendon Press, 1979.

[46] S. Popineau, C. Rondeau-Mouro, C. Sulpice-Gaillet, M.E.R. Shanahan, Free/bound water absorption in an epoxy adhesive, Polymer. (Guildf). 46 (24) (2005) 10733-10740.

[47] E. Richaud, P. Gilormini, M. Coquillat, J. Verdu, Crosslink density changes during the hydrolysis of tridimensional polyesters, Macromol. Theory Simulat. 23 (5) (2014) 320-330.

[48] H. Antheunis, J.-C. van der Meer, M. de Geus, A. Heise, C.E. Koning, Autocatalytic equation describing the change in molecular weight during hydrolytic degradation of aliphatic polyesters, Biomacromolecules 11 (4) (2010) 1118-1124.

[49] J. El Yagoubi, G. Lubineau, F. Roger, J. Verdu, A fully coupled diffusion-reaction scheme for moisture sorption-desorption in an anhydride-cured epoxy resin, Polymer. (Guildf). 53 (24) (2012) 5582-5595.

[50] J. El Yagoubi, G. Lubineau, A. Traidia, J. Verdu, Monitoring and simulations of hydrolysis in epoxy matrix composites during hygrothermal aging, Composites Part A 68 (2015) 184-192.

[51] K.H.G. Ashbee, F.C. Frank, R.C. Wyatt, Water damage in polyester resins, Proc. Royal Soc. A 300 (1463) (1967) 415-419.

[52] F. Bélan, V. Bellenger, B. Mortaigne, J. Verdu, Y.S. Yang, Hydrolytic stability of unsaturated polyester prepolymers, Comp. Sci. Technol. 56 (7) (1996) 733-737.

[53] K.A. Scott, K.T. Paul, Weathering resistance of plastics composites. Article 6 in the series - Composite materials and the designer, Composites 5 (5) (1974) 201-208.

[54] T. Nakagawa, M. Goto, Recycling thermosetting polyester resin into functional polymer using subcritical water, Polym. Degrad. Stability 115 (2015) 16-23.

[55] H.U. Sokoli, M.E. Simonsen, E.G. Søgaard, Towards understanding the breakdown and mechanisms of glass fiber reinforced polyester composites in sub-critical water using some of the most employed and efficient additives from literature, Polym. Degrad. Stability 152 (2018) 10-19.

[56] A. Baudry, J. Dufay, N. Regnier, B. Mortaigne, Thermal degradation and fire behaviour of unsaturated polyester with chain ends modified by dicyclopentadiene, Polym. Degrad. Stability 61 (3) (1998) $441-452$.

[57] Y.-F. Shih, R.-J. Jeng, Thermal degradation behaviour and kinetic analysis of unsaturated polyesterbased composites and IPNs by conventional and modulated thermogravimetric analysis, Polym. Degrad. Stability 91 (4) (2006) 823-831.

[58] J.S. Arrieta, E. Richaud, B. Fayolle, F. Nizeyimana, Thermal oxidation of vinyl ester and unsaturated polyester resins, Polym. Degrad. Stability 129 (2016) 142-155. 
[59] J.-L. Gardette, B. Mailhot, J. Lemaire, Photooxidation mechanisms of styrenic polymers, Polym. Degrad. Stability 48 (3) (1995) 457-470.

[60] G. Papet, L. Jirackova-Audouin, J. Verdu, Diffusion controlled radiochemical oxidation of low density polyethylene-I: depth dependence of morphological changes, International Journal of Radiation Applications and Instrumentation. Part C, Rad. Phys. Chem. 29 (1) (1987) 65-69.

[61] L. Audouin, V. Langlois, J. Verdu, J.C.M. de Bruijn, Role of oxygen diffusion in polymer ageing: kinetic and mechanical aspects, J. Mater. Sci. 29 (1994) 569-583.

[62] V. Langlois, M. Meyer, L. Audouin, J. Verdu, Physical aspects of the thermal oxidation of crosslinked polyethylene, Polym. Degrad. Stability 36 (3) (1992) 207-216.

[63] S. Pauly, The radiation resistance of thermoset plastics-III. Oxygen permeation experiments, Int. J. Rad. Applicat. Instrument. Part C. Rad. Phys. Chem. 39 (3) (1992) 269-272.

[64] H.-P. Gilfrich, H. Wilski, The radiation resistance of thermoset plastics- VI. Unsaturated polyester plastics, Int. J. Rad. Applicat. Instrument. Part C. Rad. Phys. Chem. 39 (5) (1992) 407-411.

[65] A. Charlesby, V. Wycherley, The irradiation of unsaturated polyester resins, Int. J. Appl. Radiat. Isot. 2 (1) (1957) 26-34.

[66] K. Bagheri, S.M. Razavi, S.J. Ahmadi, M. Kosari, H. Abolghasemi, Thermal resistance, tensile properties, and gamma radiation shielding performance of unsaturated polyester/nanoclay/ $\mathrm{PbO}$ composites, Rad. Phys. Chem. 146 (2018) 5-10.

[67] S. Michaille, P. Arlaud, J. Lemaire, Photolyse et photo-oxydation de polyesters insatures-1. Comportement du polymaleate de propylene glycol reticule ou non, Eur. Polym. J. 28 (3) (1992) $321-331$.

[68] S. Michaille, P. Arlaud, J. Lemaire, Photolyse et photo-oxydation de polyesters insatures-2. Comportement du polymaleate-isophtalate de propylene glycol reticule ou non, Eur. Polym. J. 29 (1) (1993) 35-46.

[69] A. François-Heude, E. Richaud, E. Desnoux, X. Colin, A general kinetic model for the photothermal oxidation of polypropylene, J. Photochem. Photobiol. A 296 (2015) 48-65.

[70] S. Michaille, Z. Khalil, J. Lemaire, P. Arlaud, Photolysis and photo-oxidation of unsaturated polyesters, Makromolekular Chemie Macromolecular Symposium 25 (1989) 263-269.

[71] G. Geuskens, D. Baeyens-Volant, G. Delaunois, Q. Lu-Vinh, C. David, Photo-oxidation of polymers-I: a quantitative study of the chemical reactions resulting from irradiation of polystyrene at $253.7 \mathrm{~nm}$ in the presence of oxygen, Eur. Polym. J. 14 (4) (1978) 291-297.

[72] E. Richaud, F. Farcas, P. Bartoloméo, B. Fayolle, L. Audouin, J. Verdu, Effect of oxygen pressure on the oxidation kinetics of unstabilised polypropylene, Polym. Degrad. Stability 91 (2) (2006) 398-405.

[73] S. Korcek, J.H.B. Chenier, J.A. Howard, K.U. Ingold, Absolute rate constants for hydrocarbon autoxidation. XXI. Activation energies for propagation and the correlation of propagation rate constants with carbon-hydrogen bond strengths, Revue canadienne de chimie 50 (14) (1972) 2285-2297.

[74] E. Richaud, B. Fayolle, J. Verdu, J. Rychlý, Co-oxidation kinetic model for the thermal oxidation of polyethylene-unsaturated substrate systems, Polym. Degrad. Stability 98 (5) (2013) 1081-1088.

[75] M.H. Tabankia, J.-L. Gardette, Photo-chemical degradation of polybutyleneterephthalate: Part 1—Photooxidation and photolysis at long wavelengths, Polym. Degrad. Stability 14 (4) (1986) 351-365.

[76] J. Sampers, E. Hutten, P. Gijsman, Accelerated weathering of unsaturated polyester resins. Aspects of appearance change, Polym. Testing 44 (2015) 208-223. 